\title{
AN OILSPILL RISK ANALYSIS FOR THE WESTERN GULF OF ALASKA (KODIAK ISLAND) OUTER CONTINENTAL SHELF LEASE AREA
}

\section{By JAMES R. SLACK, RICHARD A. SMITH, AND TIMOTHY WYANT}

U.S. GEOLOGICAL SURVEY

Open-File Report 77-212

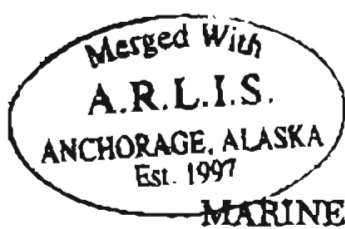




\section{U.S. DEPARTMENT OF THE INTERIOR \\ CECIL D. ANDRUS, Secretary}

\section{GEOLOGICAL SURVEY}

V.E. McKelvey, Director

For additional information write to:

Chief Hydrologist

U.S. Geological Survey, WRD

410 National Center

Reston, Virginia 22092 


\section{CONTENTS}

Page

Abstract ..............................

Introduction...............................

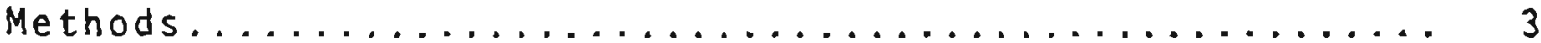

Spill frequency estimates................... 3

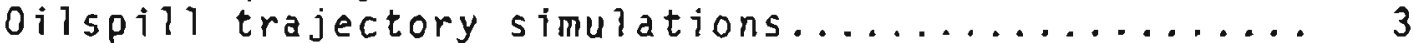

Locations of biological and recreational resources.. 5

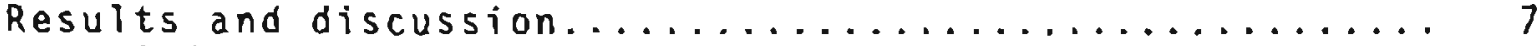

spill frequency estimates................... 7

Recent trends in spill statistics................ 10

0ilspill trajectories......................... 12

oilspill trajectories in relation to biological

resources and recreation areas............... 17

Estimates of weathering rates and slick dispersion.. 17

Combined analysis: spill frequency estimates and

oilspill trajectories...................... 22

Relative risks of leasing in different parts of

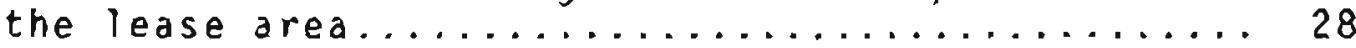

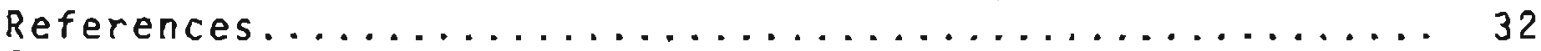

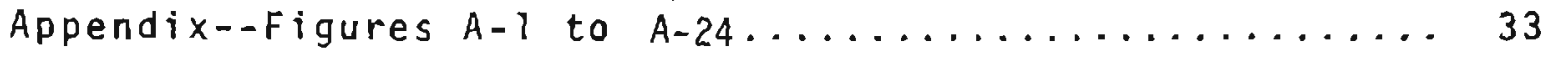

\section{ILLUSTRATIONS}

Figure 1. Map of the Western Gulf of Alaska Outer Continental Shelf showing subdivision of the lease area $(1-10)$ and the midpoints of two possible oil transport routes to

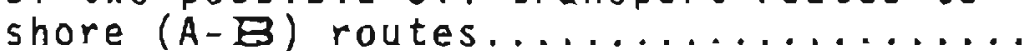

2. Spill frequency distribution for platform and pipeline spills greater than 1,000 bbls during the production life of the

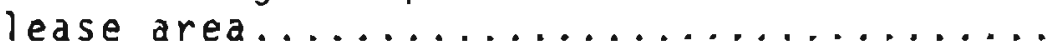

3. Spils frequency distribution for platform and tanker spills greater than l,000 bbls during the production life of the lease

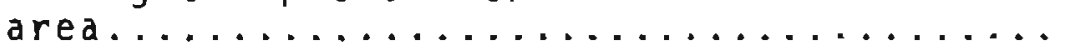

4. Example oilspill trajectory results for a spill site near the center of the proposed lease area: winter conditions. Number on trajectory reaching the coast gives time to land in days................... 13 
Page

Figure 5. Example oilspili trajectory results for a spiti site near the center of the proposed lease area: spring conditions... 14

6. Example oilspill trajectory results for a spill site near the center of the proposed lease area: summer conditions... 15

7. Example oilspill trajectory results for a spill site near the center of the proposed lease area: autumn conditions... 16

8. Probability that an oilspill occuring in the Kodlak lease area will come ashore at various geographic locations.......... 18

9. Density of beached oil along idealized shoreline as a function of travel time

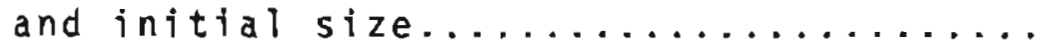

10. Probability distribution on frequency of landings for oilspills greater than 1,000 bbls over the production life of the Kodiak lease area. Based on pipeline transport.

\section{TABLES}

Table 1. 0ilspill frequency estimates by potential source for the Kodiak lease area based on distributions of Devanney and

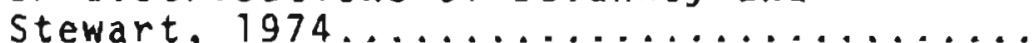

2. Percent probabilities that an oilspill occurring at potential production areas in the Western Gulf of ATaska lease would impact important biological

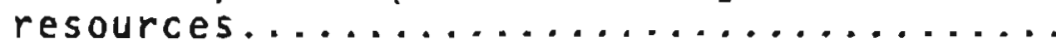

3. Mean time to shore (in days) for spills originating in the Western Gulf of Alaska. 21 


\section{TABLES--Continued}

Page

Table 4. Probabilities of one or more spilis

greater than 1,000 bbls occurring and

impacting important resources in the

Western Gulf of Alaska over the

production 1 ife of the lease area.......

5. Probabilities of one or more spills larger

than 1,000 bbl occurring and impacting

fish and shellfish resources in, the

Western Gulf of Alaska area within 3

days of spill occurrence...............

6. Ranking of $/ \theta$ subdivisions of the lease

area on the basis of oilspill risk to

biological resources................. 
AN OILSPILL RISK ANALYSIS FOR THE WESTERN GULF OF ALASKA (Kodiak Island)

OUTER CONTINENTAL SHELF LEASE AREA

BY

James R. Slack, Richard A. Smith, and Timothy Wyant

\section{ABSTRACT}

An oilspill risk analysis was conducted to determine relative environmental hazards of developing oil in different regions of the Western Gulf of Alaska Outer Continental Shelf lease area. The study analyzed probability of spill occurrence, likely path of pollutants from spills, and locations in space and time of recreational and biological resources likely to be vulnerable. These results are combined to yield estimates of the overall oilspill risk associated with development of the lease area. While the analysis includes estimates of weathering rates and slick dispersion, the methodology has not yet been developed to analyze the mitigating effects of cleanups which if taken into account would reduce the impact probabilities.

\section{INI'RODUCTION}

The Federal Government has proposed to lease 3.2 miliion acres of Outer Continental Shelf (OCS) 1 ands off Kodiak Island in the Western Gult of Alaska tor oil and gas development. Estimated recoverable petroleum resources for the proposed 564 tract sale area range from 250 million to 1.9 billion barrels. Contingent upon actual discovery of this quantity of oil, production is expected to span a period of about 25 years.

Oilspil1s clearly represent one of the major concerns associated with offshore oil and gas development in the Western Gulf of Alaska. An important fact that stands out when one attempts to evaluate the significance of accidental 
oil spillage for this, or any proposed lease area, is that the problem is fundamentally protabilistic. A great deal of uncertainty exists, for example, concerning the number and size of spilis that might occur during the course of development, as well as the wind and current conditions that would exist and give direction to the oil slick at the specific times spills do occur. While some of the uncertainty reflects incomplete and imperfect data, considerable uncertainty is simply inherent in the problem.

In view of the inability to predict with certainty future oilspill impacts, it is important to consider the range of possible impacts that could accompany oil and gas development, paying particular attention to "worst case" conditions. It is equally important, however, in attempting to maintain perspective on the problem, to associate these potential impacts with quantitative estimates of the probability of their occurrence.

This report summarizes results of an oilspill risk analysis conducted for the Kodiak (Western Gulf of Alaska) OCS lease sale. The study had the objective of determining relative risks associated with oil and gas development in different regions of the proposed lease area and was undertaken to facilitate final selection of tracts to be offered for sale. The analysis was conducted in three more or less independent parts corresponding to different aspects of the overall problem. The first part dealt with the probability of spill occurrence, the second with likely spill trajectories for the times and places spills might occur, and the third part with the spatial and temporal location of specific biological and recreational resources thought to be vulnerable to oil spilis. Results of the individual parts of the analysis were then combined to give estimates of the overall oilspill risk associated with oil and gas development in the lease area.

Much of the data and information used in the analysis were compiled by the U.S. Bureau of Land Management in the course of preparing the environmental statement for the Kodiak sale. These results, then, represent synthesis and analysis of existing information rather than presentation of new material.

We would like to express special appreciation to 3 ames Seidl of the U.S. Bureau of Land Management for his assistance in gathering the necessary data and information for the study. 
A detailed mathematical description of the models used in this analysis is given in a forthcoming U.S. heological Survey Circular (Smith and others, 1976.) The present discussion focuses on the conceptual framework of the models, and on data sources and limiting assumptions.

\section{Spizz Erequency Estimates}

Statistical distributions tor estimating probabilities of oilspill occurrence were taken from Devanney and Stewart (1974) and Stewart (1975). In addition to the fundamental assumption that realistic estimates of future spill frequency can be based on past OCS experience, use of these distributions requires the further, specific assumptions that spills occur independently of each other (as a poisson process), and that accident rate is dependent on volume of oil produced and handled.

Spill frequency estimates were calculated separately for ten subdivisions of the proposed lease area (fig. 1 ) based on estimated petroleum resources for individual prospects within those areas (U.S. Geological survey, proprietary data). Use of the Devanney and Stewart distributions permitted separate estimates of platform, pipeline, and tanker spill frequency which could then be combined to compare the two alternative modes of transport of crude to shore. Spill frequency estimates were further categorized for spills between 50 and 1.000 bbls, and greater than 1,000 bbls in size. The size grouping is somewhat arbitrary but, as discussed below, is very important in considering the significance of weathering in reducing oilspill impacts.

\section{Oilapizl Trajectory Simulations}

An oilspill trajectory model was constructed and used to analyze movements of hypothetical oil sicks on a digital map of the Western Gulf of Alaska between about 1 at $55^{\circ}$ to $61^{\circ} \mathrm{N}$. and about long $147^{\circ}$ to $157^{\circ} \mathrm{W}$. The coordinate system for this area was established with a grid size of 1 nautical mile (nmi). Surface current velocity fields were provided by National Oceanic and Atmospheric Administration. Short-term patterns in wind variability were characterized 


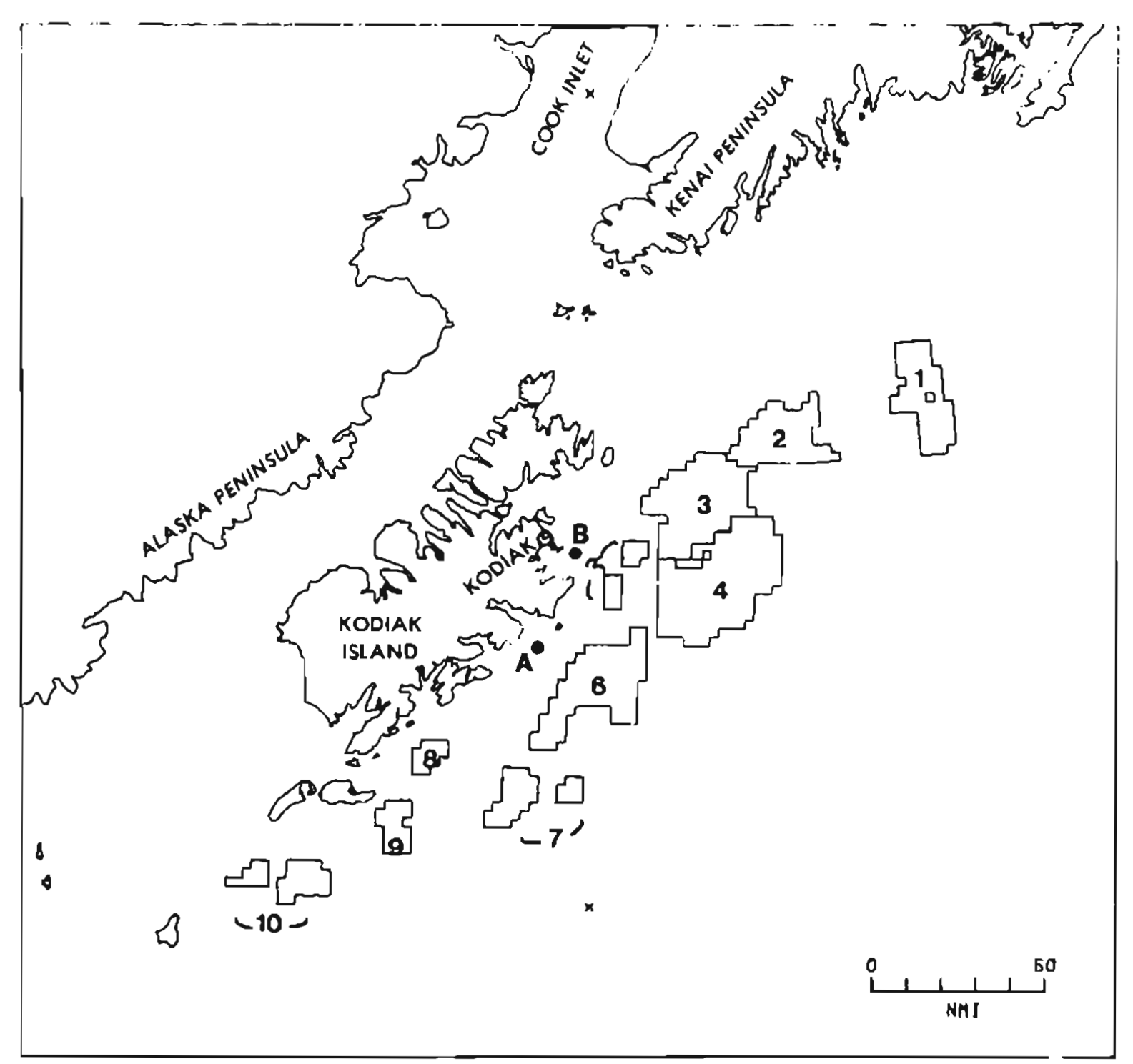

Figure 1.--Map of the Western Gulf of Alaska Outer Continental Shelf showing subdivisions of the lease area $(1-10)$ and the mid-points of two possible oil transport routes to shore $(A-B)$. 
with a probability matrix for successive 3 -hour velocity transitions (first order Markov process). Wind transition matrices were evaluated from U.S. Weather Service records from the Kodiak, Alaska and Middleton Island Alaska weather stations ( 5 years continuous record each) and were established separately tor four seasons.

Trajectories of 500 hypothetical ollspills were simulated in Monte Carlo fashion for spill sites within each of the ten subdivisions of the lease area and along two hypothetical transportation routes, under wind and current conditions (tor the four seasons), yielding a total of 24,000 trajectories. Surface transport of thie oil slick for each spill was simulated as a series of straightine displacements of a point in space, each representing the joint influence of wind and current on the siick for a 3-hour period. Wind transition probability matrices were randomly sampled each period for a new wind speed and direction, and the current velocity was updated as the spill changed location in the velocity fleld. The wind drift factor was taken to be 0.035 with a drift angle of $20^{\circ}$.

The final product of trajectory model runs consists of a large number of simulated oilspill trajectories or pathways which collectively reflect both the general trend and variability of winds and currents (see figs. 4 through 7), and which can be summarized in statistical terms. It should be emphasized that these trajectories represent only hypothetical pathways for the transport of oilslicks and do not involve any consideration of cleanup, dispersion, or weathering processes which would determine the quantity and quality of oil that may eventually come in contact with biological populations or other important resources. The significance of dispersion and weathering in mitigating oilspill impacts is discussed in more detail below.

Locations of Biological and Recreational Resources

The locations of 24 categories of biological, recreational, and other resources were digitized in the same coordinate system as that used in trajectory simulations (See Appendix A, tigs. 1-24). The monthly sensitivity of these resources (for example spawning period or pigration period) was also recorded. Resource groups were as follows: 
1 Salmon purse seining and set net areas

2 Pink and chum salmon intertidal spawning areas

3 Dungeness crab spawning, rearing and catch areas

4 Tanner crab fishing areas

5 Tanner crab mating and hatching areas

6 Tanner crab vital rearing areas

7 Tanner crab important rearing areas

8 King crab mating and hatching areas

9 King crab vital rearing areas

10 King crab important rearing areas

11 Shrimp fishing areas

12 Shrimp reproduction rearing areas

13 Seabird colonies

14 Summer bird distribution (June, July, August)

15 Fall bird distribution (September, October, November)

16 Winter bird distribution (December, January, February)

17 Spring bird distribution (March, Apri1, May)

18 Marine mammal foraging areas

19 Sea lion rookeries and hauling grounds

20 Harbor seal rookeries and hauling grounds

21 Sea otter concentration areas

22 Kelp beds

23 Foreign fishing areas

24 Archeological sites 


\section{RESULTS AND DISCUSSIUN}

Spill Frequency Estimates

The probability distribution on the frequency of oilspills greater than 1,000 bbls in size during the production life of the proposed lease area is given in figure 2. Probabilities apply to the total of production platform spills and pipeline spills assuming transport of the total product to shore via pipeline. Although transport by pipeline is the preferred method, tanker or barge transport is considered a possibility, at least for the early years of production. The corresponding frequency distribution for the total of platform and tanker spills is presented in figure 3 for comparison. Means of the distributions in figures 2 and 3 are indicated with arrows. On the basis of development plans outlined in the Draft Environmental Statement for this area it was assumed that transport for sites 1-5 would pass through site $A$, and that transport for sites 6-10 would pass through site B (see fig. 1 ).

In the absence of refinery construction in the Western Gulf of Alaska region, it is expected that any crude oil transported by pipeline from the lease area to storage facilities on shore would be subsequently carried by tanker from these terminals to existing refinexies elsewhere. Thus it should be noted that in addition to the spill risk associated with production and transport to shore (fig. 2), there would be a further increment of risk associated with this tanker traffic in and out of local ports. An estimate of tanker spill frequency based on estimated production from Kodiak oil fields is given in table 1 . Only a fraction of this risk applies to the immediate region, however, the remainder being distributed along the tanker routes to refineries, and within the estuaries and ports where terminals are located.

One of the advantages of making predictions about oilspill frequency in the form of a probability distribution is that such data give not only an estimate of the most likely number of spilis that would be expected to occur but some measure of the uncertainty that exists about that prediction. Figure 2 , for example, indicates that the expected number of spilis greater than 1,000 bbls is about 7-8 spills (mean of 7.5), but that there is only about 14 -percent probability that there would be exactly 7 spills, about 13 -percent probability that there would be exactly 8 


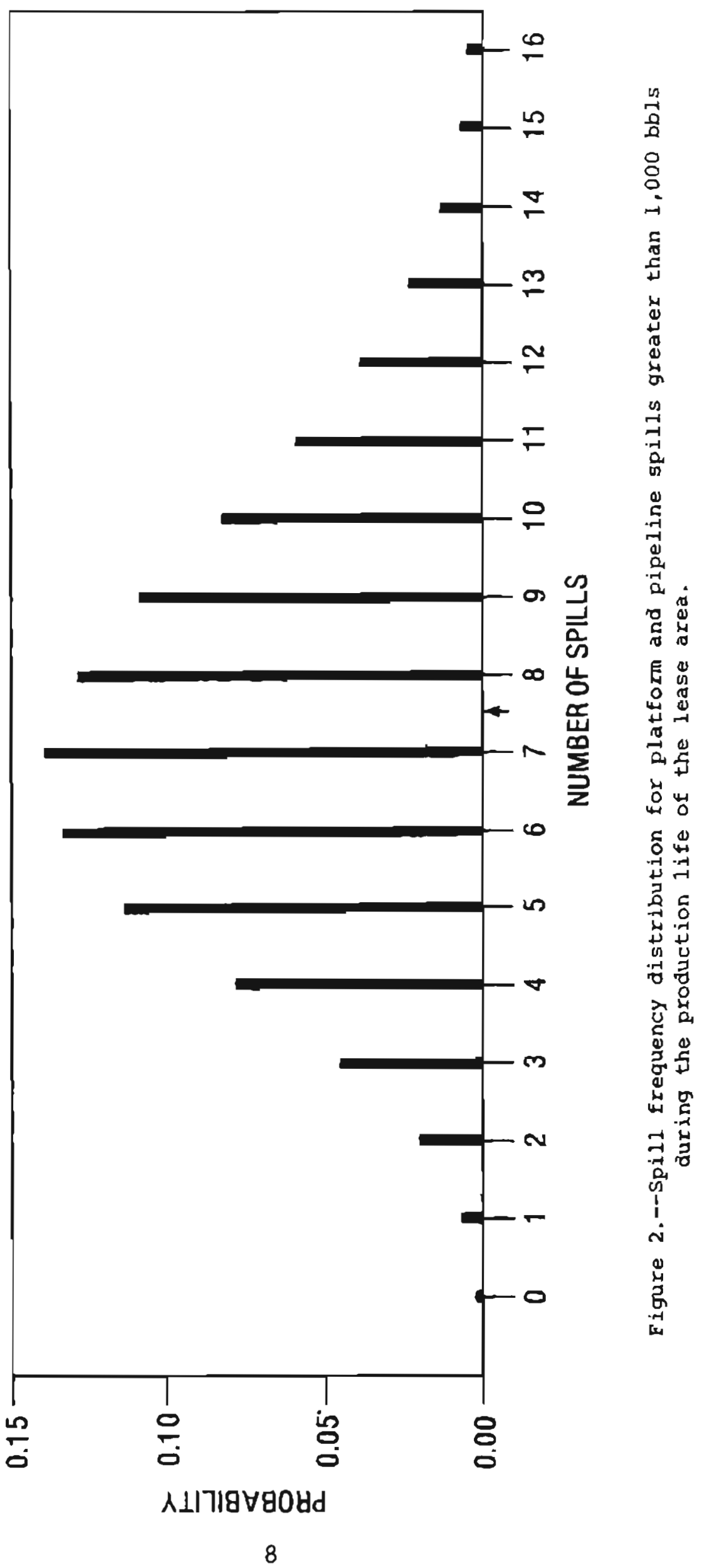




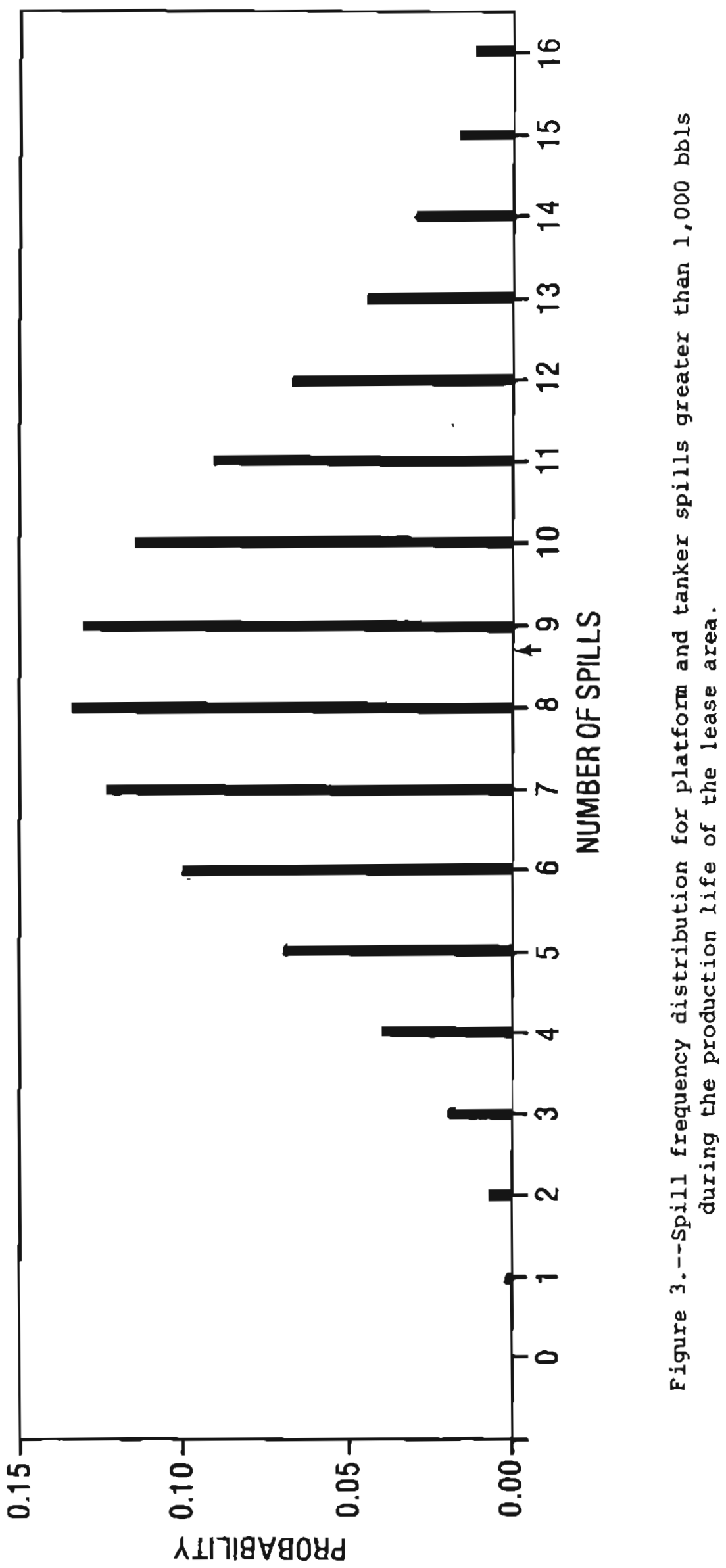


spil1s, and 62-percent chance the number would be anywhere trom 5 to 9 spills (obtained by suming the probabilities over that range). Noting that the probability of zero oilspilis greater than 1,000 bbls is less than 1 percent, one can conclude that the probability of at least one spill (that is sum of the probabilities for one and greater) is very near 100 percent. Again, these probabilities apply to the sum of platform and pipeline spills larger than 1,000 bbls over the estimated field life of the total proposed lease area. A breakdown of these data for platform, pipeline, and tanker spills appears in table lA. Expected frequencies for spills in the size range 50-1,000 bb1s and less than 50 bbls over the production life of the total area are giver in tables $1 B$ and $1 C$. Available sources do not provide for a meaningful separation of pipeline and platform spill statistics for spills smaller than 1,000 bbls.

Recent Trends in Spizl Statistics

AII of the above figures are subject, of course, to the validity of earlier stated assumptions, the most important of these being that accident rates per unit production of future Gulf of Alaska fields would be the same as those observed to date in other areas. One might question this assumption either from the point of view that safety records might be expected to improve with time, or from the standpoint that accident rates are not transferrable to a newly opened OCS area.

With regard to the question of improvement in accident rates, recent statistics from Coast Guard Files show no clear trend in spill frequency for production platforms and pipelines during the period 1971-75. Spill frequency estimates given above (table l) for platform and pipeline spills were based on Gulf of Mexico statistics for the years 1971 and 1972, for which the accident rate was 3.6 incidents per million barrels produced and handled (all sizes). The corresponding accident rates for the years 1973-75 were 3.9, 4.2 and 3.2 incidents per million barrels respectively. Trends in spill frequency for larger spill sizes are similarly difficult to identify. Geological survey records for spills of $50 \mathrm{bbls}$ and larger in the Gulf of Mexico OCS list $11,2,4,8$, and 2 incidents respectively for the years 1971 through 1975 , a period during which offshore production gradually declined from 387 to 315 miliion bols year, (Vanenberger, 1976 ). 
Table 1 ( $A, B$, and C).--Oilspill frequency estimates by potential source for the kodiak lease area based on distributions of Devanney and Stewart, 1974.

Expected Number
Probability of at least one spill

A. Spills $>1,000$ bbis

$\begin{array}{lcc}\text { Platforms } & 3.6 & .97 \\ \text { Pipelines } & 3.9 & .98 \\ \text { Tankers } & 5.2 & 9 \\ \text { Platforms \& Pipelines } & 7.5 & 9 \\ \text { Platforms \& Tankers } & 8.8 & 9\end{array}$

B. Spills 50-1,000 bbls

Platforms \& Pipelines

Tankers

C. Spills $0-50$ bbls (mean size approx. = 1 bbl:

Platforms \& Pipelines

5,465

Tankers

656

$g$ Greater than 99.5 percent probability. 
It should also be pointed out that while the total volume of oil spilled in small oCS incidents (less than 50 bbls) declined quite steadily from about 1,500 bbls to about 700 bbls per year between 1971 and 1975 , the total annual volume lost in the oCs spills of ali sizes has been extremely variable and shows no decipherable trend. Total volume spilled increased from less than 3,000 bbls per year in 1971 and 1972 to more than 23,000 bbis per year in 1973 and 1974, then declined again to less than 1,000 bbls in 1975 (Danenberger, 1976).

There is evidence, however, of recent improvement in the incidence of tanker spills. 'Frequency estimates given above for tanker spills were based on world statistics for the years 1969-72 (spills over 1,000 bbls) and U.S. Coast Guard data for the years $1971-72$ ( 5 p111s under 1,000 bbls) for which the overall accident rate was 0.45 incidents per million barrels handled (a11 sizes; Devanney and Stewart, 1974). The corresponding rate for the years 1973-74 was on $1 y$ about 0.07 incidents per militon barrels, although some of the apparent improvement is due simply to a change in the method of estimating volumes of crude handled in U.S. ports (Stewart, 1976).

\section{Oilspill Trajectories}

The results of trajectory model runs consist of a large number of hypothetical oilspill trajectories $(24,000)$ which collectively reflect both the general trend and variability of winds and currents and which can be described in statistical terms. Ten trajectories based on wind and current conditions for each of the four seasons have been randomly selected as examples from a total of 2,000 trajectories released from location 5 near the center of the lease area and are shown in figures 4.-7. The patterns evident in the trajectory simulations are roughly similar over all seasons and all sites tending either south or south-west depending on whether the simulated spili moves outside the lease area away from Kodiak lsland or not. Those trajectories that happen to move toward shore tend to wander about in the region extending from the lease area to the Kodiak coast. Those trajectories that move east (and south) of the tracts quickly travel south-southwest, leaving the area of consideration.

The spatial disposition of is shown in figure 8. The final location of each trajectory 


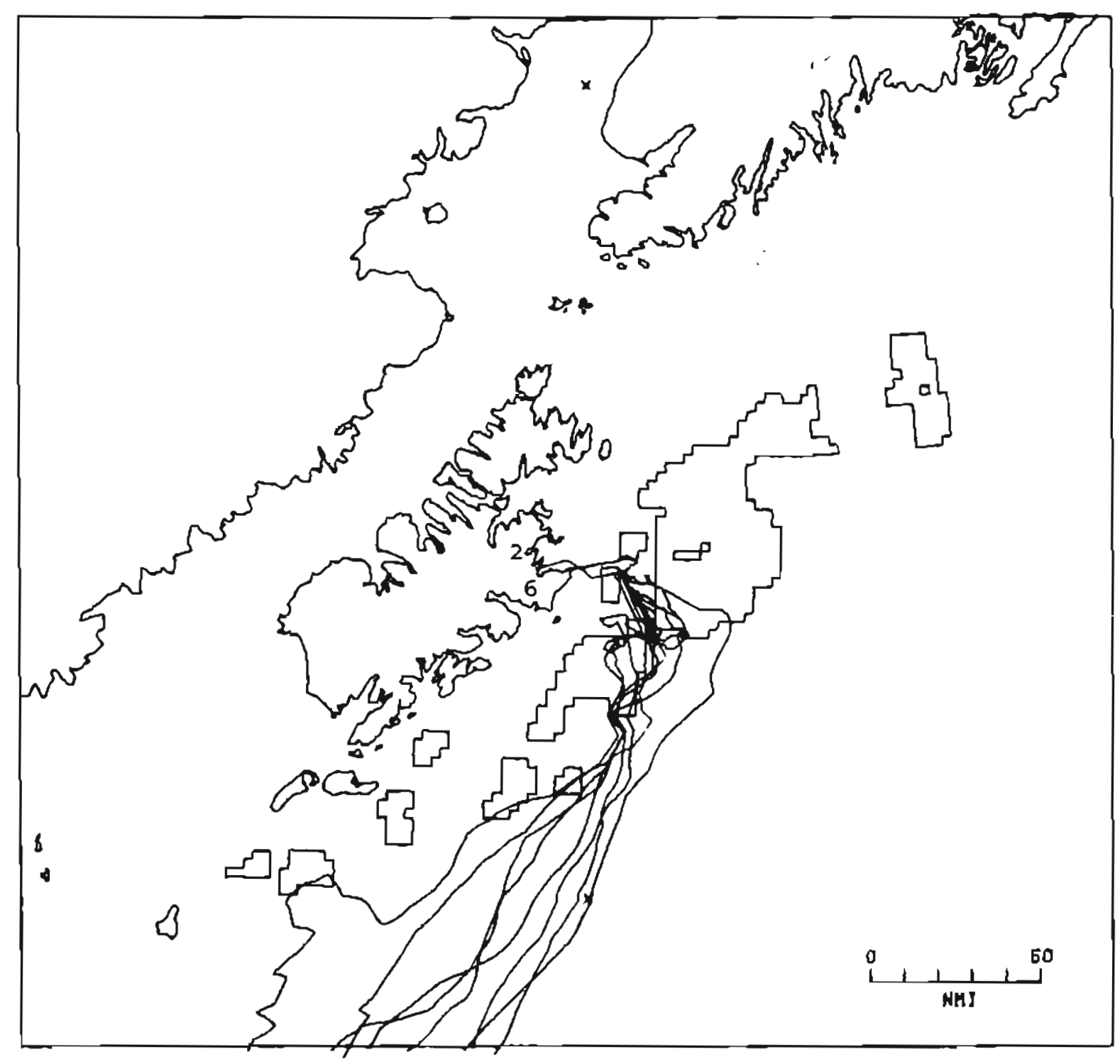

Figure 4.--Example oilspill trajectory results for a spill sice near the center of the proposed lease area: winter conditions. Number on trajectory reaching the coast gives time to land in days. 


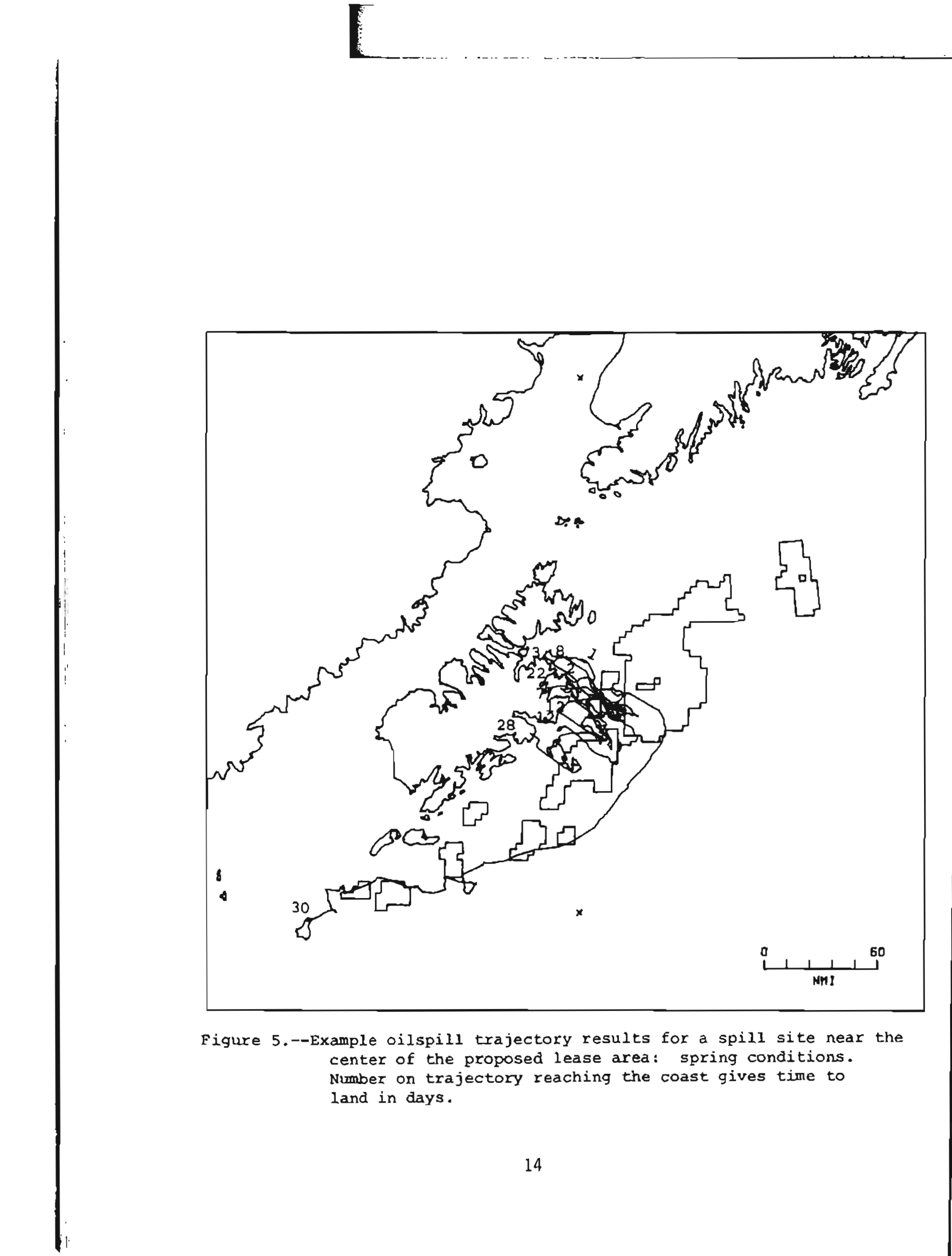




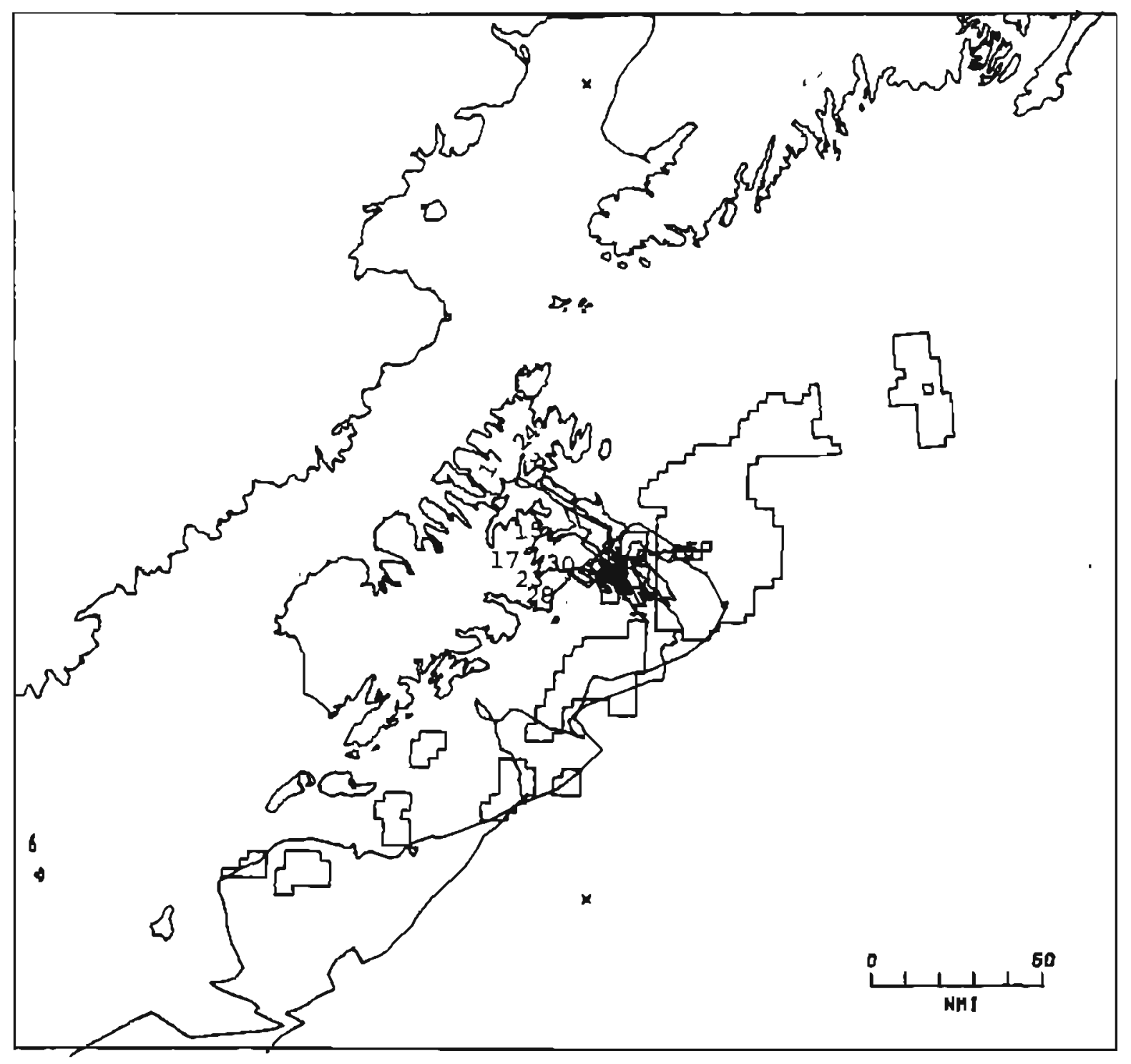

Figure 6.--Example oilspill trajectory results for a spill site near the center of the proposed lease area: summer conditions. Number on trajectory reaching the coast gives time to land in days. 


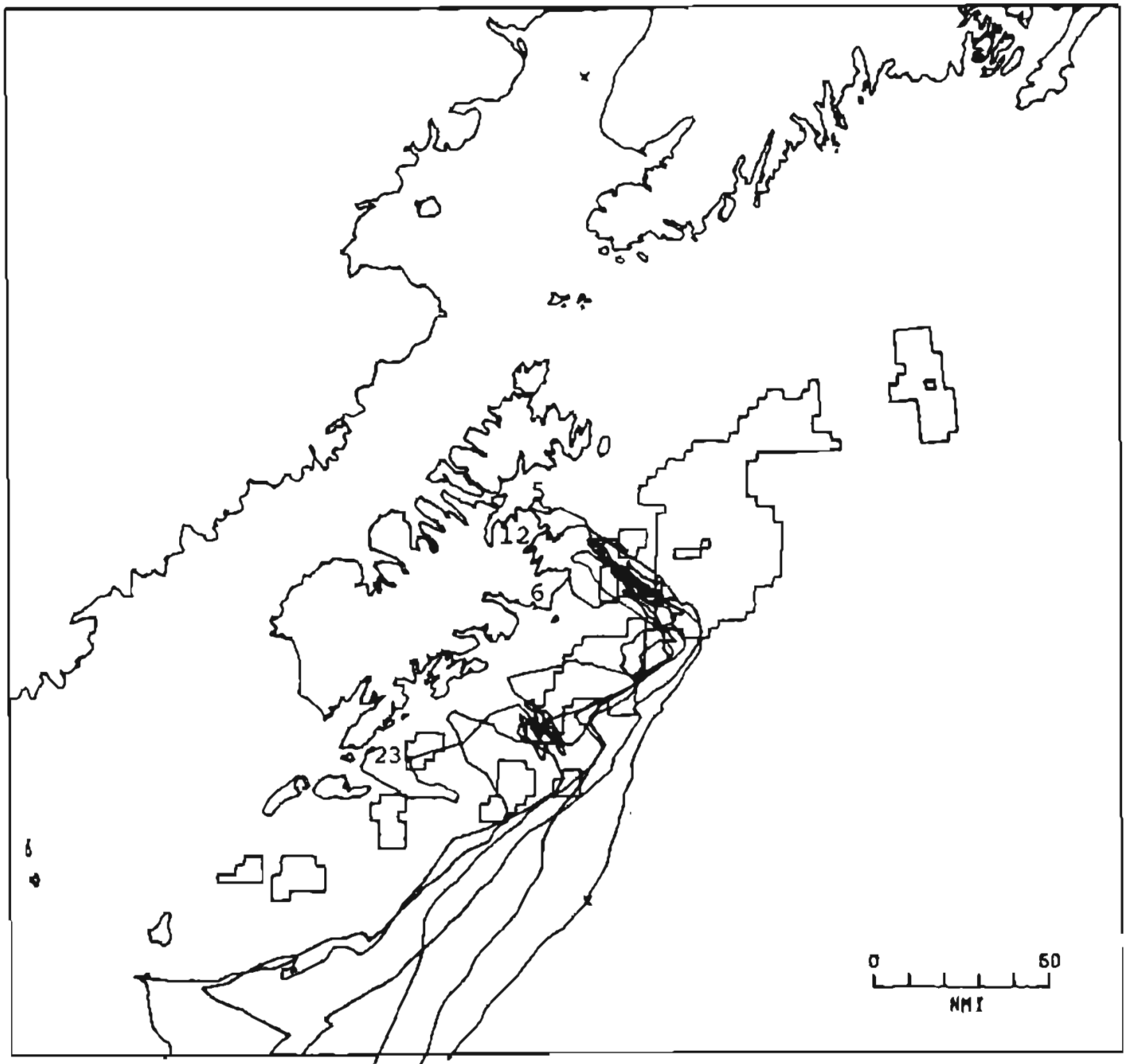

Figure 7.--Example oilspill trajectory results for a spill site near the center of the proposed lease area: autumn conditions. Number on trajectory reaching the coast gives time to land in days. 
was recorded and the results for specific sections of the coastline were expressed as a percent of the total. Thus, according to figure 8,12 percent of the spills trajected ashore on or near Afognak Island, 11 percent on northern Kodiak coast, about 4 percent on the Southern Kodiak coast about 6 percent on the Trinity Islands, and about 7 percent on Chirikof Island. Two percent of the trajectories were left at sea; that is after 90 days of tracking they had neither beached or left the map. The tendency for trajectories to travel south-southwest, as seen in figures 4-7, is reflected in figure 8. About 56 percent of the simulated spilis left the area of consideration by traveling south and southwest from the lease area. Heading in this direction the spilis would be in the open waters of the Pacific ocean.

Oilspiz Trajectories in Relation to Biological Resources and Reoreation Areas

Oilspill trajectory simulations were conducted keeping track of the frequency with which trajectories intersected the locations of biological and recreational resources. Trajectories were recorded as impacting a resource only in cases where the resource was 1 isted as being vulnerable to oilspills in the month the impact took place. Table 2 gives the probability of impact on each of the 25 categories of biological resources, recreation areas, and other objects for a spill originating at the twelve spill sites within the lease area (see fig. 1). As one would expect, the likelihood that a given spill trajectory would beach at the location of a specific land-based resource during critical seasons is generally smaller than the 44 percent probability of coming ashore anywhere.

Estimates of Weathering Rates and slick Dispersion

It must be emphasized that up to this point the analysis has dealt only with trajectories for the transport of surface oil by winds and currents and has not involved any consideration of dispersion or weathering processes which would progressively. reduce the quantity of oil contained in the slick as it traveled towards shore. The probabilities given in table 2, theretore, represent a worst-case analysis in the sense that some fraction of the spills occurring more than 50 miles offshore in the lease area would be expected to deteriorate to the point of 


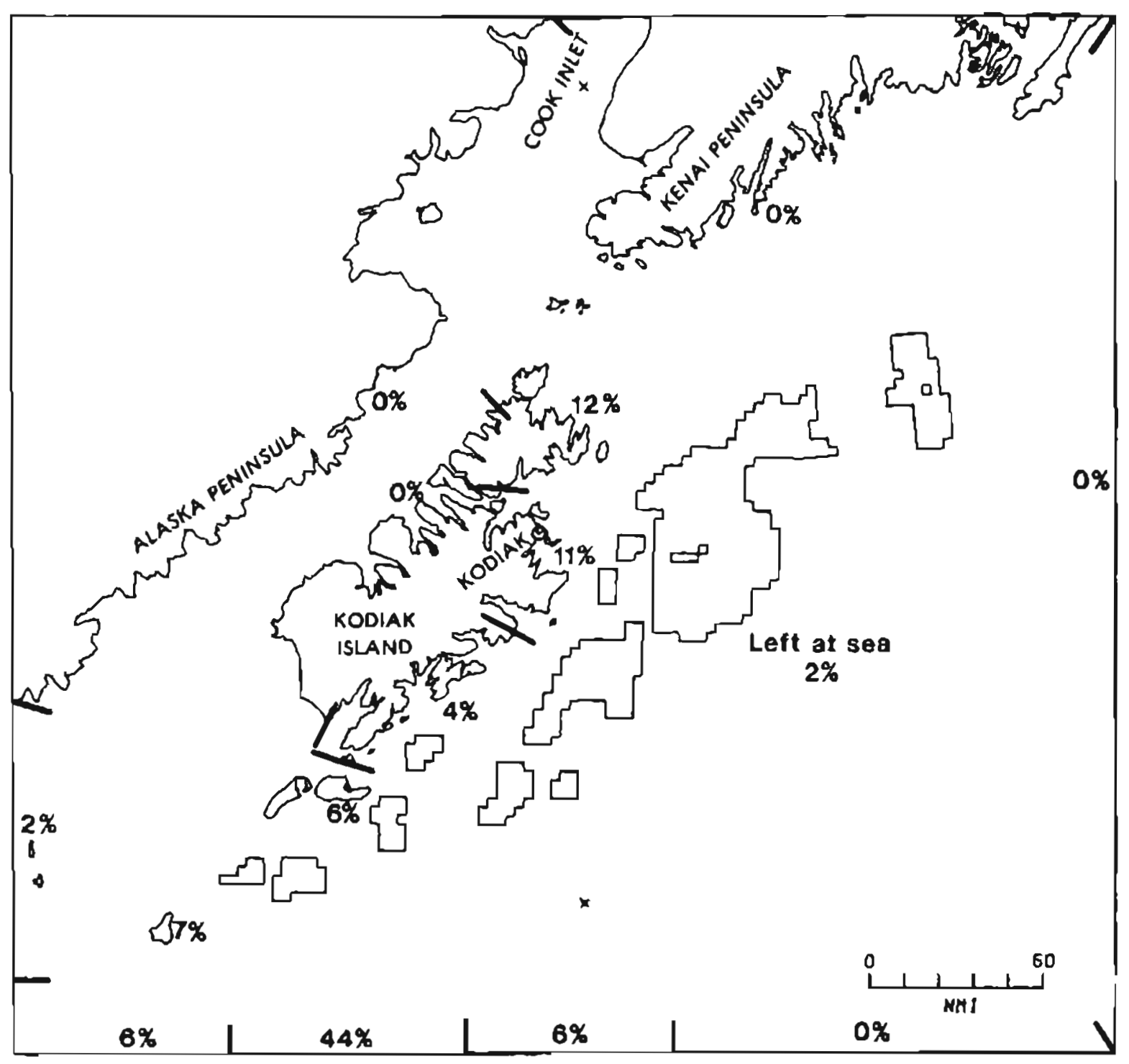

Figure 8.--Probability that an oilspill occurring in the kodiak lease area will come ashore at various geographic locations. 


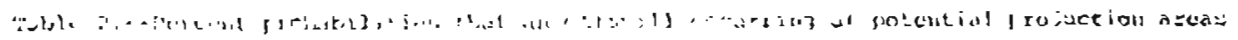

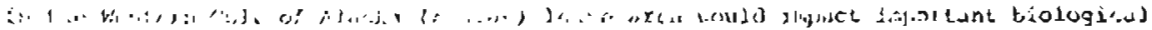

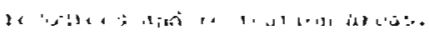

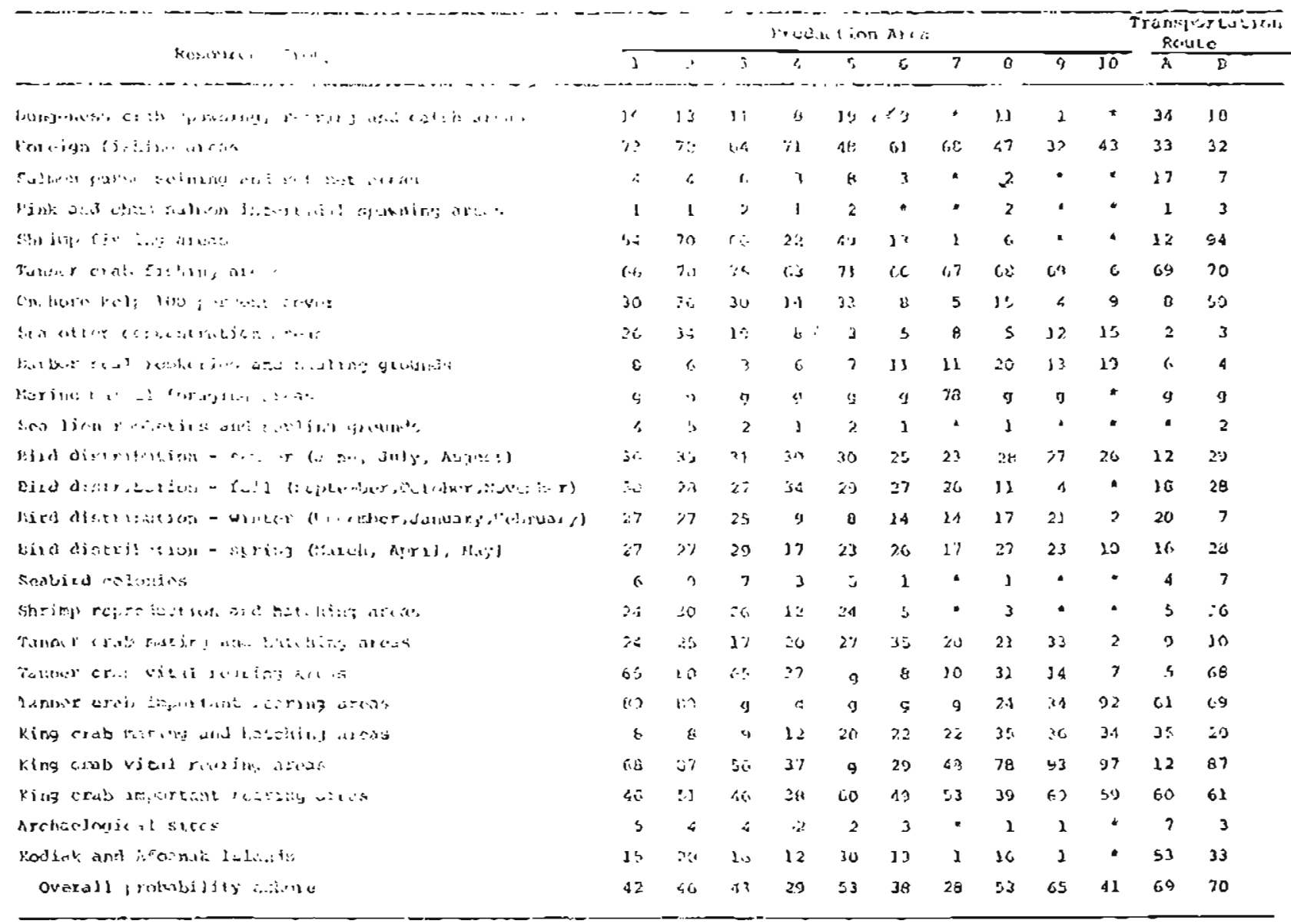

- Less timn ถ.

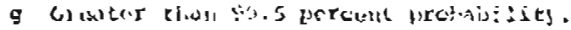


insignificance before reaching land. Some attempt at quantifying weathering and dispersive etfects and accounting for them in probability estimates is thus in order.

One important factor determining the signjticance of weathering in reducing oilspill impacts is the time required for spills to reach land. Times to land for simulated trajectories, in fact, covered a very wide range, and it is therefore particularly important to consider this tactor in interpreting results of the spill trajectory analysis. Table 3 shows the mean number ot days at sea for trajectories which reached the coast within 90 days from the spill sites. The mean time to land from the production areas seems to be determined primarily by the distance of the site from land modified by how far south the site is relative to Kodiak Island. 'lhat is, as discussed above, the simulated spills have a strong southerly tendency so that spills originating at the southern sites must reach land quickly if they are to do so before leaving the area of consideration.

Included in the list of factors which would determine the potency of spilis at the time of impact hould be spill size of course, as well as the quality or composition of the oil since lighter weight crudes evaporate at a much more rapid rate than those with a large proportion of high molecular weight hydrocarbons. This latter factor is hard to predict in advance and the significance of weathering is therefore difficult to quantity despite its obvious importance in interpreting these results. Also, the dispersion of a spili and the likelihood that it would impact a resource are potentially reduced by cleanup efforts, but this mitigating factor is not incorporated in the probability analysis.

The most important conclusion to be reached Erom the data in table 3 is that times to shore for most spills wil be so long that they will no longer exist as an identifiable slick but rather will have fragmented into a large number of discrete particles or "blobs" by the time any oil arrives on shore. Observations by Jeffery (1975) of actual spills in the North Atlantic indicate breakup of the slick can be expected within about 4 days, and that the particies of residual oil typically consist of spongy emulsions of oil of widely varying sizes. Moreover, it is generally agreed that large fractions of the original volume of oil will evaporate in the first few days of weathering and that further loss to the atmosphere occurs at a very slow rate. Data from Nelson 
Table 3.--Mean time to shore (in days) for spills originating in the Western Gulf of Alaska.

\begin{tabular}{|c|c|c|c|c|c|}
\hline & \multirow[b]{2}{*}{ site } & \multicolumn{4}{|c|}{ Season } \\
\hline & & Winter & Spring & Summer & Autumn \\
\hline \multirow{11}{*}{ 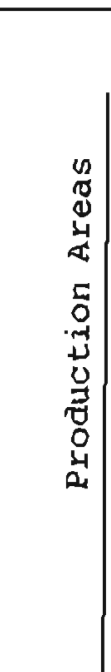 } & & & & $2^{2}$ & \\
\hline & 1 & 30 & 42 & 36 & 29 \\
\hline & 2 & 33 & 41 & 35 & 31 \\
\hline & 3 & 25 & 31 & 30 & 25 \\
\hline & 4 & 16 & 29 & 34 & 19 \\
\hline & 5 & 12 & 18 & 18 & 11 \\
\hline & 6 & 10 & 13 & 18 & 10 \\
\hline & 7 & 12 & 14 & 15 & 13 \\
\hline & 8 & 8 & 10 & 12 & $g$ \\
\hline & 9 & 6 & 6 & 5 & 6 \\
\hline & 10 & 5 & 5 & 4 & 5 \\
\hline \multirow{3}{*}{ 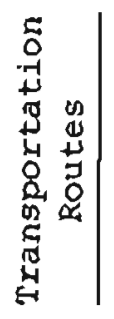 } & & & & & \\
\hline & A & 5 & 6 & 7 & 5 \\
\hline & B & 7 & 13 & 10 & 8 \\
\hline
\end{tabular}


(1958) Eor crude oil of API gravity $40^{\circ}$, for example, indicate about 50 percent of the original spill volume would be lost to evaporation.

Thus for oil spills in the Kodiak lease area it would appear that an important consideration is the extent to which fragments of the slick are dispersed by the time they reach shore. Using lateral dispersion coefticients from Csanady (1974) estimates of slick dispersion were made for various travel times and for two spill sizes, 1,000 bbls and 50 bbls, assuming 50 percent 1055 of the original volume by evaporation. The resulting distribution of oil along an assumed straight shoreline is given in figure 9 . It is important to note that the protiles will tlatten considerably as the coastline becomes more irregular. In any case, it appears that residual oil from a single spill as small as 50 bbls would not be easily detected on the beach after 30 days at sea.

Combined Analysis: Spill Frequency Estimates and Oilspizl Trajectories

It is worth briefly sumarizing some of the important points to be drawn from the results presented thus far. Data in table 1 indicate that although more than 5,500 oilspill incidents would be expected during the course of oil production in the Western Gulf of Alaska, only a very few are likely to exceed 1,000 bbls. Furthermore, consideration of travel time to shore (table 3 ), evaporation rates, and rates of slick dispersion (fig. 9) leads to the conclusion that an individual spill would need to be as large as 1,000 bbls in size in orcer to have significant ecological impact. The probabilities in table 2 give the chances that if a major spill occurs in the lease area it would come ashore and hit any of various important resources.

With respect to the hazard of major spills (that is, greater than 1,000 bbls), the data presented in table? represent only a partial solution to the proolem of assessing oilspill risks to important resources. The overall oilspill risk posed by oil and gas development in the proposed sale area must be assessed as a joint function of the probability that spills will occur in the course of development as well as the likelinood that spills will tollow certain trajectories. Thus, the data in table 2 must be combined with the spill trequency estimates presented in 

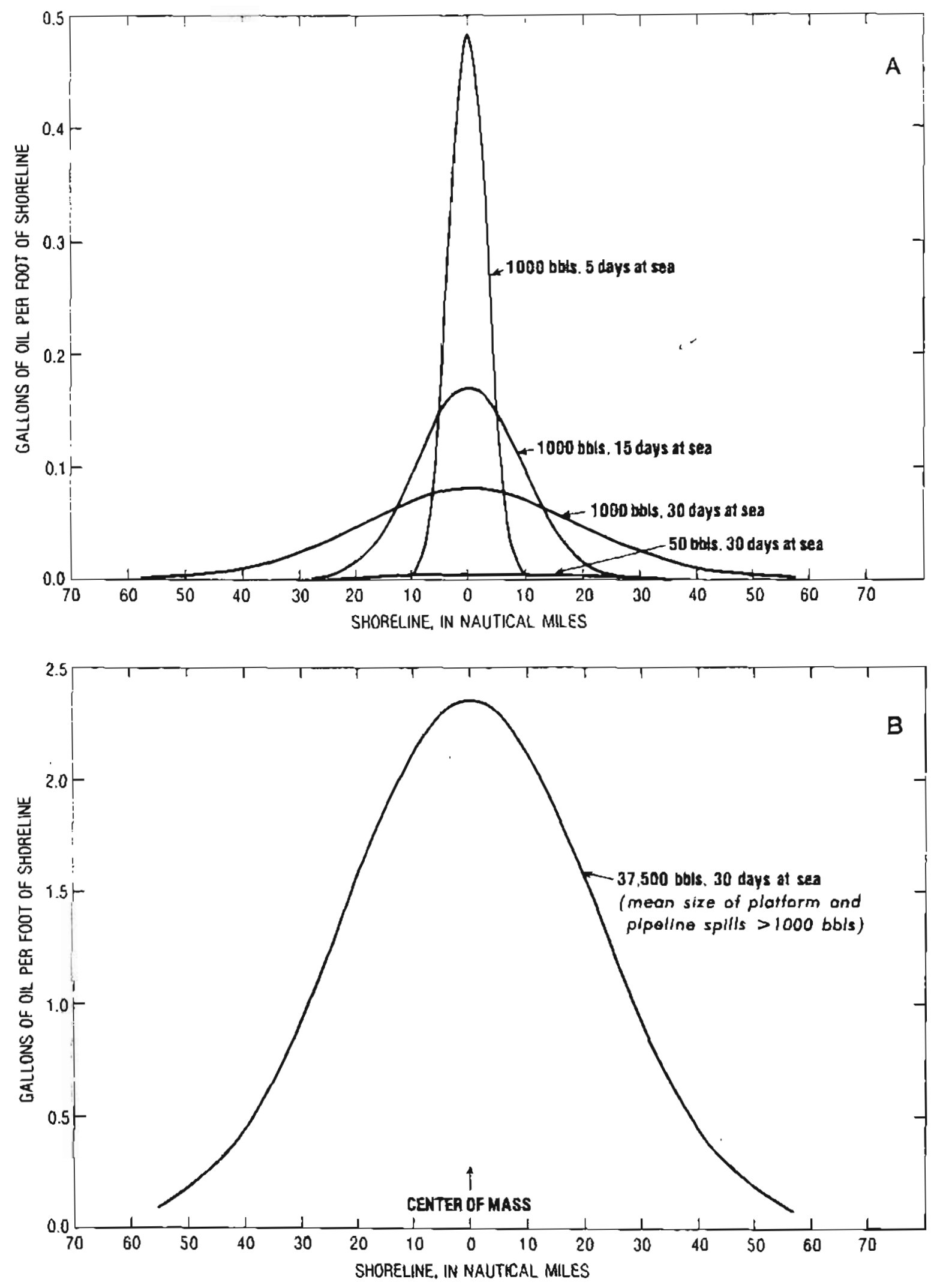

Figure 9.--Density of beached oil along ldealized shoreline as a function of travel time and inttial size. 
figures 2 and 3 above to obtain a total probability distribution for impacts on specufic resources.

Despite the intuitive logic of simply multiplying the probabilities in figure 2 by those in table 2 , the correct computation of the overall or "total" probability is in fact somewhat more complicated. This results from the fact that the probabilities presented in table 2 are actually conditional probabilities and refer to the probabilities of impacts on resources "conditioned" on the chance of spills occurring in the tirst place. The overall probability that oilspills will impact a particular resource exactly k times during the production life of the area, $P(k)$, is given by

$$
P(k)=\sum_{n=k}^{\infty} P(k \mid n) P(n)
$$

where $P(k \mid n)$ is the probability of $k$ impacts on the resource given the occurrence of $n$ spills, and $P(n)$ is the probability of $\pi$ spilis occurring. The conditional probability $P(k \mid n)$ can be assumed to be distributed binomially and is giver by

$$
P(k \mid n)=\left(\begin{array}{l}
n \\
k
\end{array} p^{k}(1-p)^{n-k}\right.
$$

where $p$ is the probability of impact on the resource given the occurrence of a spill (table 2).

The combined probability distribution calculated in the above manner for spilis coming ashore is presented in figure 10. The distribution is based on spill frequency estimates from figure 2 and therefore refers to impacts from all spills originating as 1,000 bbls or greater during the production life of the total lease area and assumes pipeline transport to shore via routes $A$ and $B$. Figure 10 indicates that there is a 3 percent probability that no oilspills greater than 1,000 bbls will occur and come ashore in the course of oil production in the proposed lease area. One can immediately conclude, therefore, the chances are 97 percent that at least one such spill would occur and come ashore during the production life ot the area (sum of the probabilities of 1 and greater). 


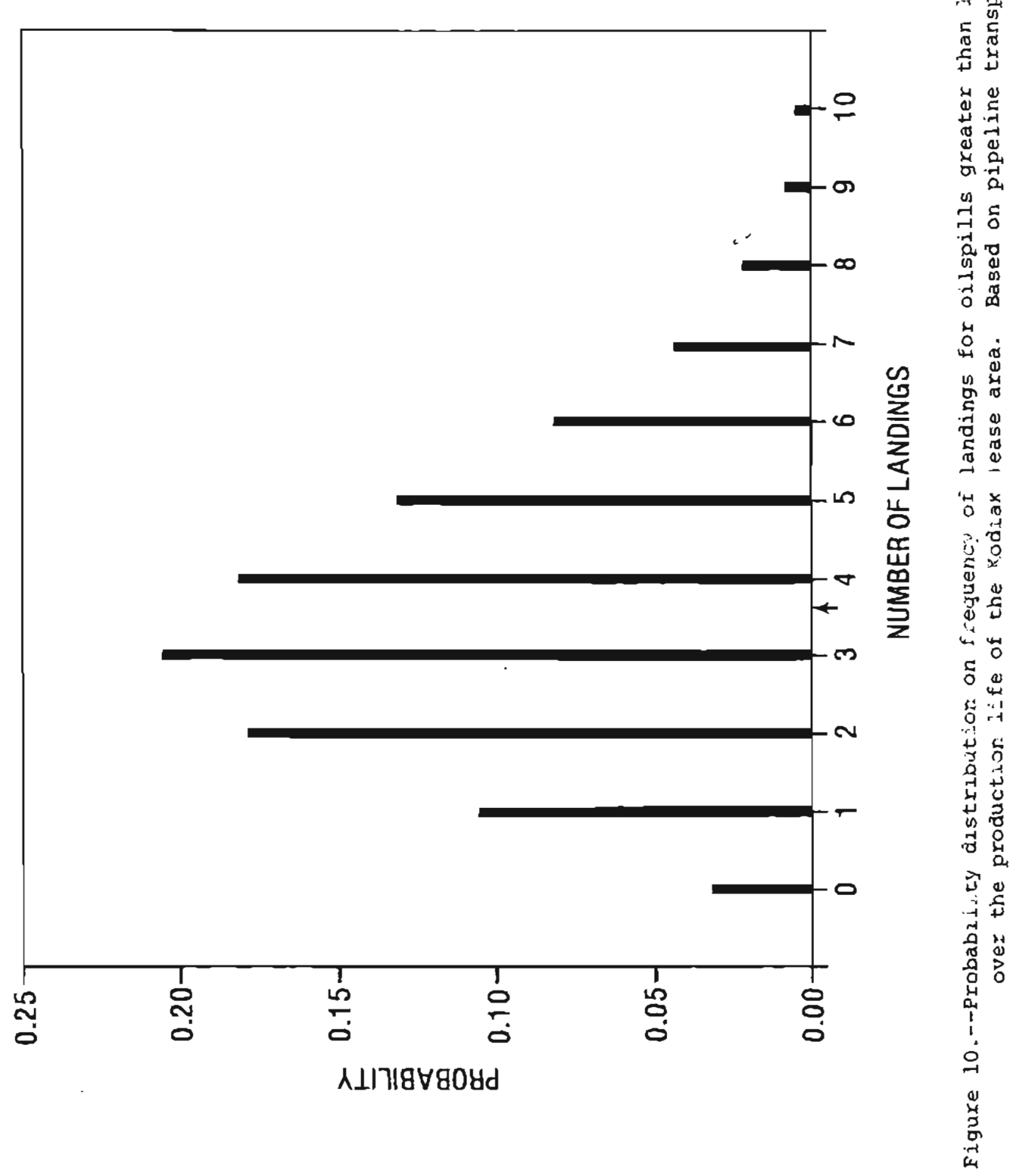


Probability distributions similar to figure $10 \mathrm{can}$ be developed and likewise interpreted for each of the 25 categories of biological resources, recreation areas, and other objects. Probabilities of at least one spill greater than 1,000 bbls occurring during the production life of the area and impacting the various resource groups are given in table 4. The data refer to the total of production and transport spills and have been calculated separately for tro alternate methods of transport of the oil from the lease area, pipeline and tanker. The assumption is made that half of all transport related spills occur in the vicinity of production platforms and half occur along transport routes to shore (sites $A$ and $B$; see above).

It is emphasized that probability estimates reter on $1 y$ to the chances that oil in some form or another, from a spill originating larger than 1,000 bbls, will come in contact with some portion of a resource thougnt to be potentially vulnerable. The mitigating effects of weathering processes and clean-up efforts are only indirectly reflected in the probabilities in table 4 by virtue of the fact that estimates apply only to large spills. Figure 9 provides a rough description ot the likely effects of evaporation and dispersion on spills of various sizes as a function of time. To this must be added the likelihood of at least some, and perhaps considerable, success in containing oil in the course of the days or weeks separating the occurrence of a spill on the OCS and its arrival on shore.

It is important that the distinction between the probabilities given in table 2 and those in table 4 be very clear. The data given in table 2 refer only to the likelihood that spilis would tollow certain trajectories and have nothing to do with the chances that spilis would occur in the first place. The probabilities in table 4, by contrast, reflect both the expected frequency of spill occurrence as well as the likelihood of certain trajectories.

While the probabilities in table 4 cover a wide range, a large number of resources show alarmingly high chances of impact from a major oilspili sometime during the 25 -year producing life of the lease area. For a majority of the resource categories ( 18 out of 24 ) the odds are estimated to be greater than 50-50 for at least one such incident, and for 9 categories the risk is greater than 90 percent. 


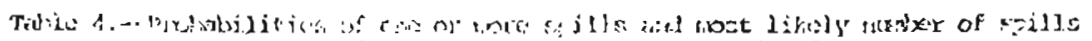

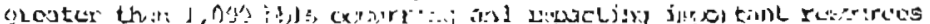

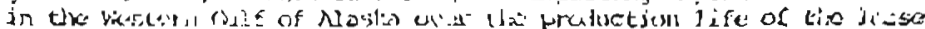
inisa.

Resource: category

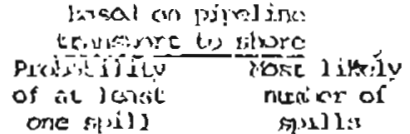

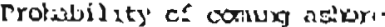

37

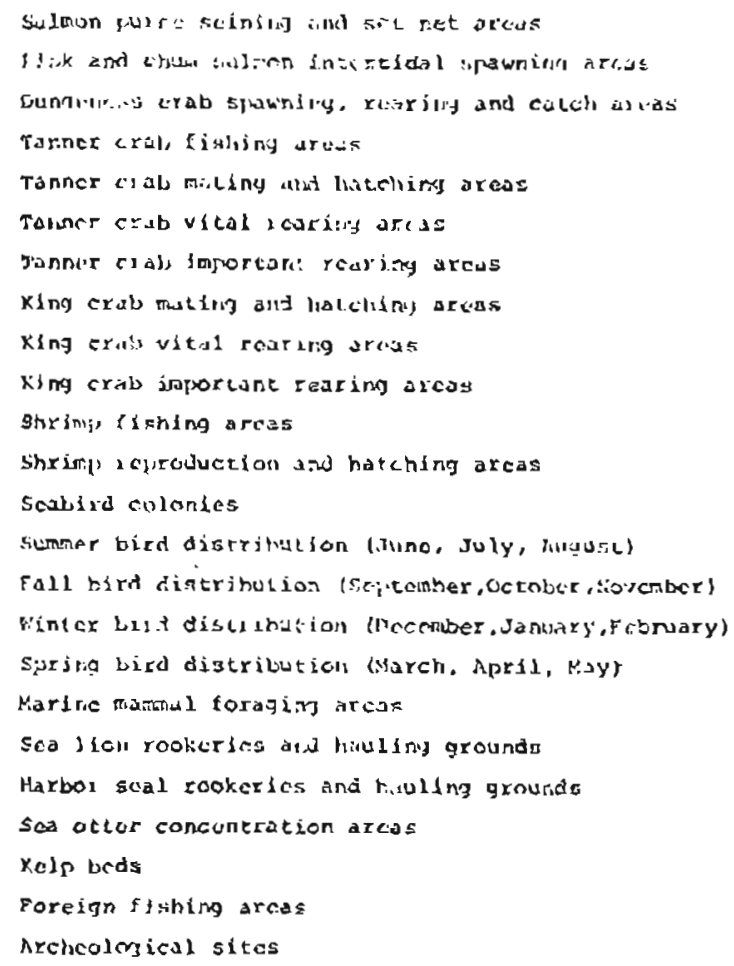

Basal on taoker trausnile to elore Probalisity poet likcly of rit lease monler of che spidl spills

- boss chan 0.5 percent.

9 Grositer Lian 99.5 perache. 
Among the resources showing high impact probabilities are a number of areas important to commercial shellfishing including spawing, rearing and harvesting grounds for shrimp, dungeness crab, tanner crab, and king crab. According to table 4, many shellfish areas would be expected to be involved in anywhere trom two to five separate major spill inciderts over the field lite. past exnerience with oilspills in shelifish areas las ranred from reportedly severe and lasting effects in the case of the rest Falnouth spill, when toxic conponents of tle oil were quickly churned into near-shore sediments (Bluner, 1970), to much more modest effects following the "Torrey Canyon" snill when more time vas available for weathering before impact (Smith, 1968 ). These differences in effects occurred despite the fact that the Torrey Canyon spilled more than 150 times the volume lost in the west Falmouth spil1.

It is apparent that organisms such as shellfish and finfish can be distinguished from other biological resources on the basis that their sensitivity to spilled crude is dependent on contact with soluable toxic components of the oil, fractions which tend to evaporate relatively rapidly from a spreading slick. Thus, it is important to consider estimates of time to impact for spil1 trajectories hitting these resources when interpreting probability estimates in table 4. In order to refine estimates of impact probability to account for weathering of toxic components of the oil, trajectory model runs were repeated to determine probability of impact within 3 days of spill occurrence. Three days is reported to be time sufficient for evaporation and dissolution of most of the toxic aromatic tractions of crude oil, with less time required under high wind conditions (Offshore Uil Task Group, 1973).

Cummulative probabliities (over the field life) of at least one impact on $f$ ish and shellfish resources within 3 days of spili occurrence are given in table 5. Although impact probabilities in most categories are much lower than those in table 4, risk levels for certain resources such as tanner crab and king crab populations are shown to be very high.

Relative Risks of Leasing in Different Parts of the Lease Area.

One objective of the present study is to elucidate the relative risks of petroleum development in different regions 
Table 5.-Probabilities (percent) of one or more spills greater than 1,000 bbls occurring and impacting biological resources in the Western Gulf of Alaska (Kodiak) area within

3 days of spill occurrence. Probability estimates are cumulative over the production

life of the lease area.

\begin{tabular}{lcc}
\hline \multicolumn{1}{c}{ Resource category } & $\begin{array}{c}\text { Eased on } \\
\text { pipeline transport } \\
\text { to shore }\end{array}$ & $\begin{array}{c}\text { Based on } \\
\text { tanker } \\
\text { transport } \\
\text { shore }\end{array}$ \\
\hline Salmon purse selning and set net areas & 17 & 22 \\
Pink and chum salmon intertidal spawning areas & 2 & 2 \\
Dungeness crab spawning, rearing and catch areas & 27 & 35 \\
Tanner crab fishing areas & 96 & 98 \\
Tanner crab mating and hatching areas & 25 & 29 \\
Tanner crab vital rearing areas & 63 & 69 \\
Tanner crab important rearing areas & 98 & 99 \\
King crab mating and hatching areas & 58 & 67 \\
King crab vital rearing areas & 80 & 85 \\
King crab important rearing areas & 83 & 90 \\
Shrimp fishing areas & 56 & 65 \\
Shrimp reproduction and hatching areas & 22 & 27 \\
Kelp beds & 13 & 17 \\
\hline
\end{tabular}


of the proposed lease area, information wnich is necessary in selecting the tracts to be offered for sale. One consideration of importance in comparing the oilspili risk associated with different potential production areas is the value or weight to be assigned to each of the biological and recreational resources, since a given tract will pose proportionally greater risk to some resources than others, depending on location. For purposes of this analysis means of the impact probability distributions for the 25 resource groups wall be averaged to give an overald index of risk for each of the subdivisions of the lease area, but it should be noted that this averaging implies an equal weighting of the resources.

It is extremely important in comparing risk values for the different subdivisions of the lease area to distinguish between two fundamentally different ways of expressing relative risks. One can compare subdivisions of the lease area on the basis ot impact probability given the occurrence of a spill using the data in table 2. This is equivalent, in fact, to making the comparison on the basis of risk per unit oil recovery, since the data in table 2 are conditioned on the occurrence of one spill and spill frequency is taken to be a direct function of oil production. Alternatively, one can make the comparison on the basis of total risk by using data computed as in table 4 wnich combine spill frequency estimates with the probabilities of observing certain trajectories.

In table 6 the 10 subdivisions of the lease area are ranked on the basis of risk to the 25 resource categorles (equally weighted) using both methods of expressing relative risk. The question of which is the most appropriate method of ranking the subdivisions of the lease area with respect to oilspill risk might be answered differently depending on one's perspective. If one is interested in the question of tradeoffs between the benefits of producing oil and the costs of possible spill impacts, then risk per unit oil is clearly of most interest. If one stands to lose a great deal personally in the event of a spill, a loss that is far out of proportion to one's expected gains from oil production, then absolute risk is of most interest. 
Table 6.--Rank ordering of 10 subdivisions of the Kodiak lease area on the basis of oilspill risk to biological resources and recreation areas. Numbered subdivisions are shown in the map in figure 1 and are 1 isted here in order of decreasing risk.

Ranking on the basis of risk per unit oil production

\begin{tabular}{c} 
Ranking on the \\
basis of total \\
risk aver the \\
estimated \\
production life \\
\hline 4 \\
2 \\
1 \\
3 \\
8 \\
5 \\
10 \\
7 \\
6 \\
9
\end{tabular}

Ranking on the basis of total risk over the estimated production life
5

1

3

4

6

8

9

7

0

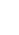

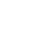

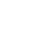

8




\section{REFEKENCES}

Csanady, G. T., 1973, Turbulent diftusion in the environment: D. Reldel Publishing Co., Ceophysics and Astrophysics Nonographs, v. 3, Boston.

Danenberger, E. P., 1976, Oil spills, 1971-75, Gult of Mexico Uuter Continental Shelf: Geological Survey Circular $741,47 \mathrm{p}$.

Devanney, J. W., III, and Stewart, R. J., 19\%, Analysis of oilspill statistics: Report to Council on Environment Quality, Wash., D. C., $126 \mathrm{p}$.

Jeffery, P. G., 1973, Large-scale experiment on the spreading of oil at sea and its disappearance by natural forces, In Proceedings of conference on Prevention and Control of oil spills (1973): p. $469-474$.

Nelson, W. L., 1958, Petroleum refinery engineering, New York, McGraw-Hi11.

Otfshore Oil Task Group, 1973, The Georges Bank petroleum study, vol. II: Massachusetts Inst. Technology Sea Grant Report, $311 \mathrm{p}$.

Ra1ph M. Parsons Laboratory, 1976, A review and evaluation of basic techniques for predicting the behavior of surface oil slicks, In Report to Deepwater Ports Office: Nat1. Oceanog. Aeronaut. Admin, $171 \mathrm{p}$.

Stewart, R. J., 1975, Oil spillage associated with the development of offshore petroleum resources, In Report to Organization for Economic Co-operation and Development: $49 \mathrm{p}$.

U.S. Department of the Interior, Bureau of Land Management, 19/7, Proposed 1977 outer continental shelf oil and gas lease sale in the Western Gulf of Alaska (OCS Draft Environmental Statement), 4 volumes. 


\section{APPENDIX \\ Figures $A-1$ to $A-24$}

The locations of biological resources in the vicinity of the Western Gulf of Alaska Outer Continental Shelf Lease Area 


\section{SALMON PURSE SEINING AND SET NET RREAS}

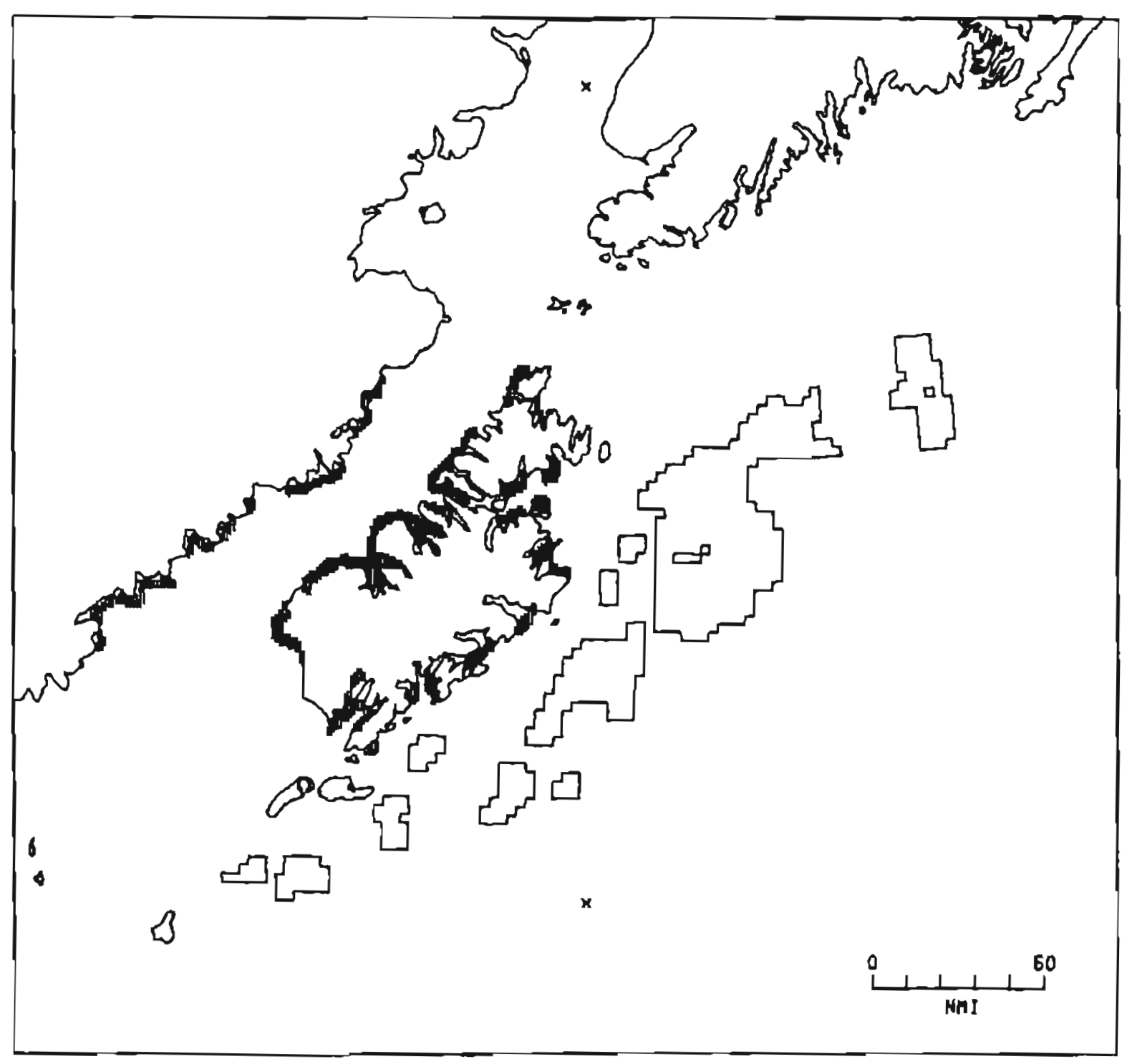

Figure A-1.--Hatched area indicates spatial extent of salmon purse seining and set net areas. 
PINK AND CHUM SALMON INTERTIDAL SPAWNING AREAS

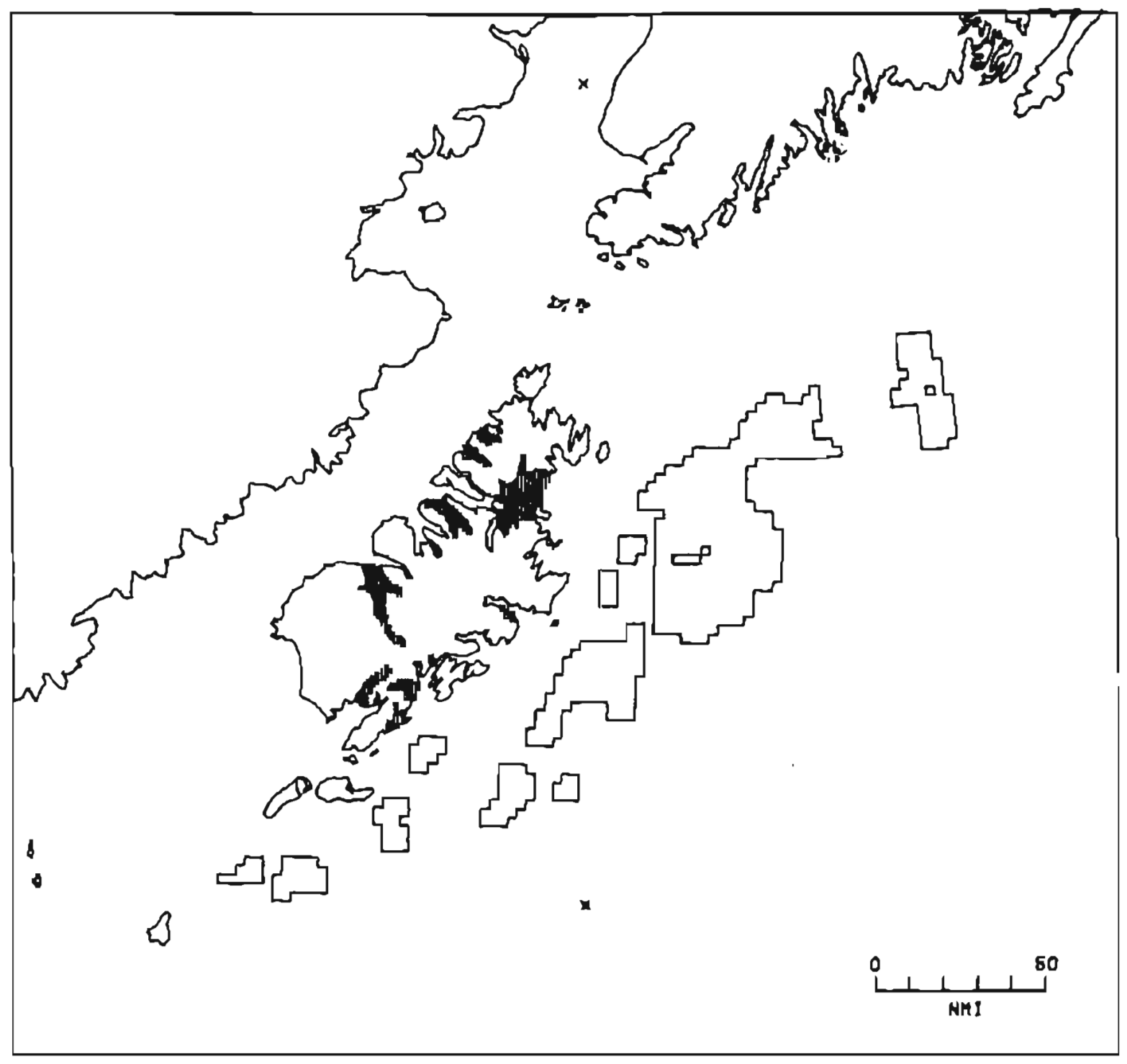

Figure A-2.--Hatched area indicates spatial extent of pink and chum salmon intertidal spawning areas. 


\section{DUNGENESS CRAB SPRWNING, REARING AND CATCH AREAS}

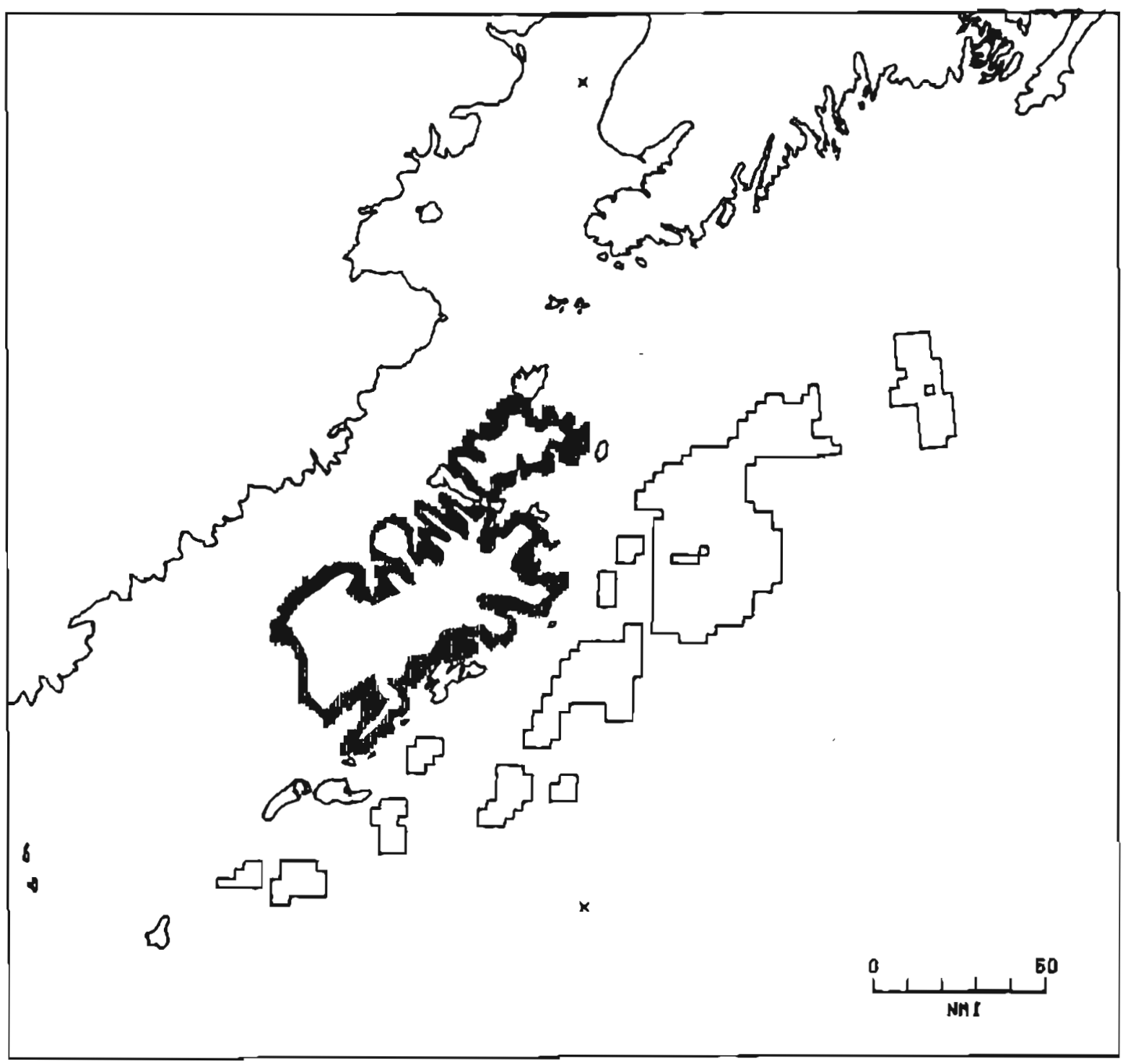

Figure A-3.- Hatched area indicates spatial extent of dungeness crab spawning, rearing and catch areas. 
TANNER CRGB FISHING AREAS

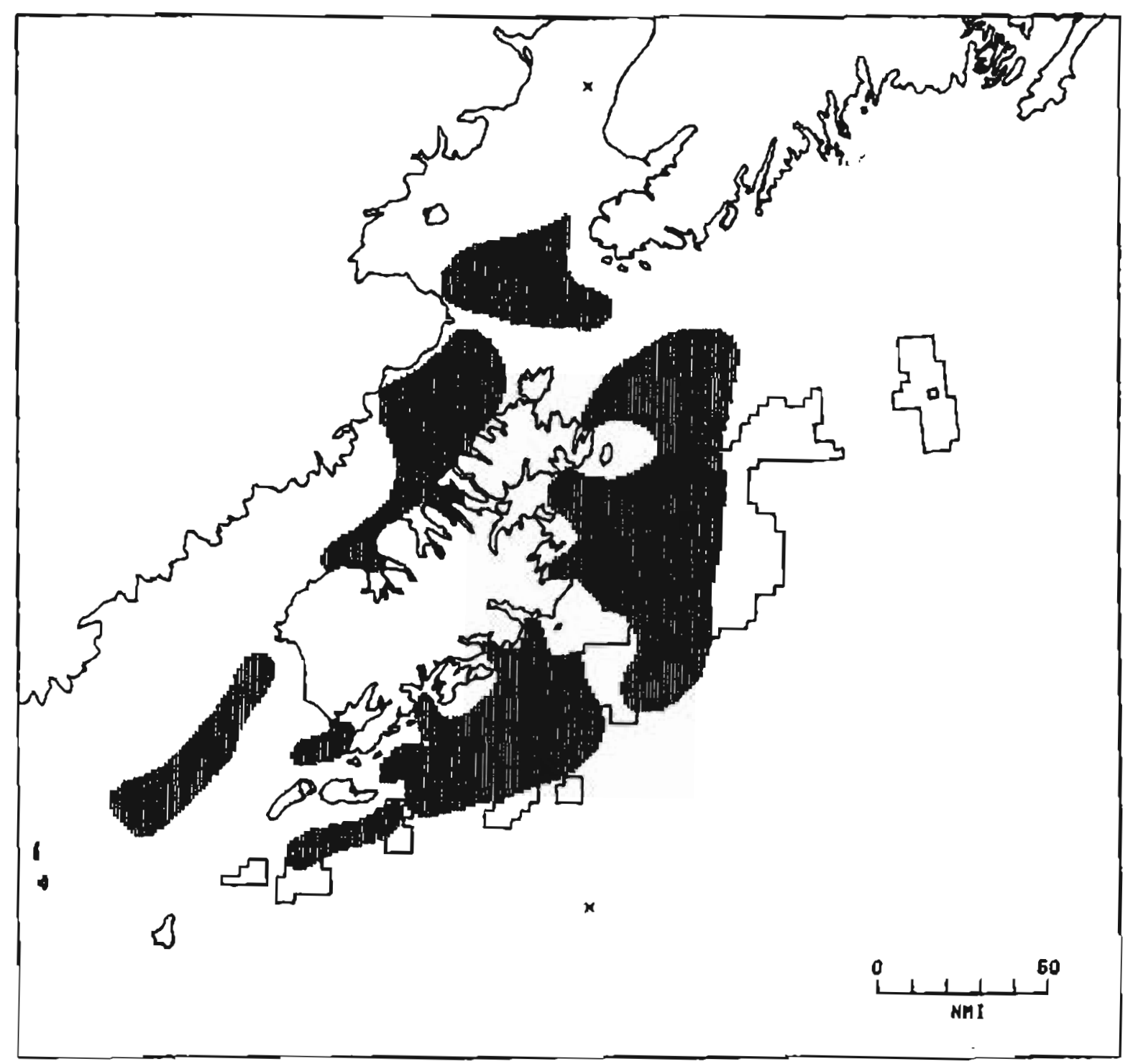

Figure A-4.--Hatched area indicates spatial extent of tanner crab fishing areas. 
TANNER CRAB MATING AND HATCHING RREAS

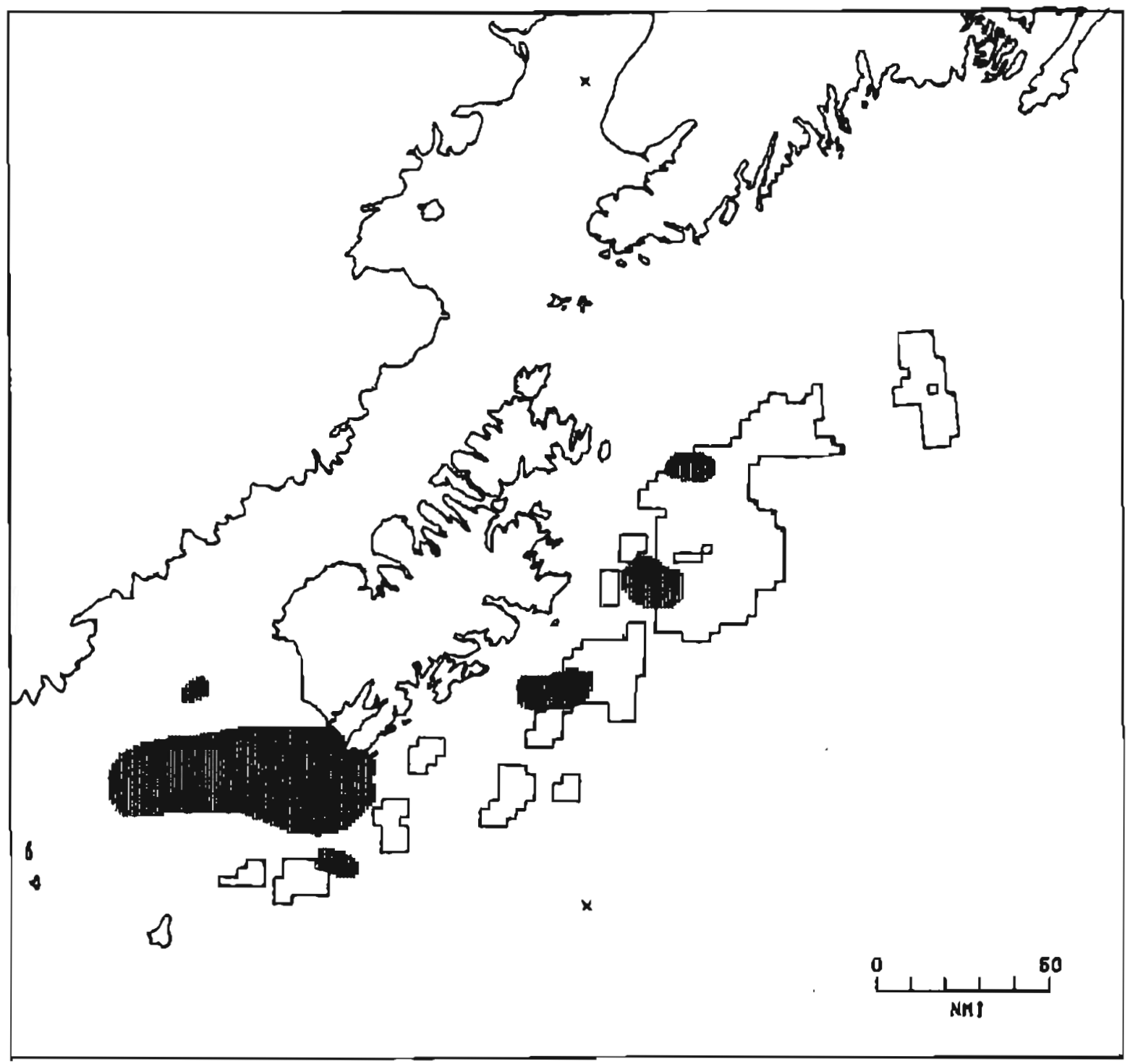

Figure A- 5.--Hatched area indicates spatial extent of tanner crab mating and hatching areas. 
TANNER CRAB VITRL RERRING RRERS

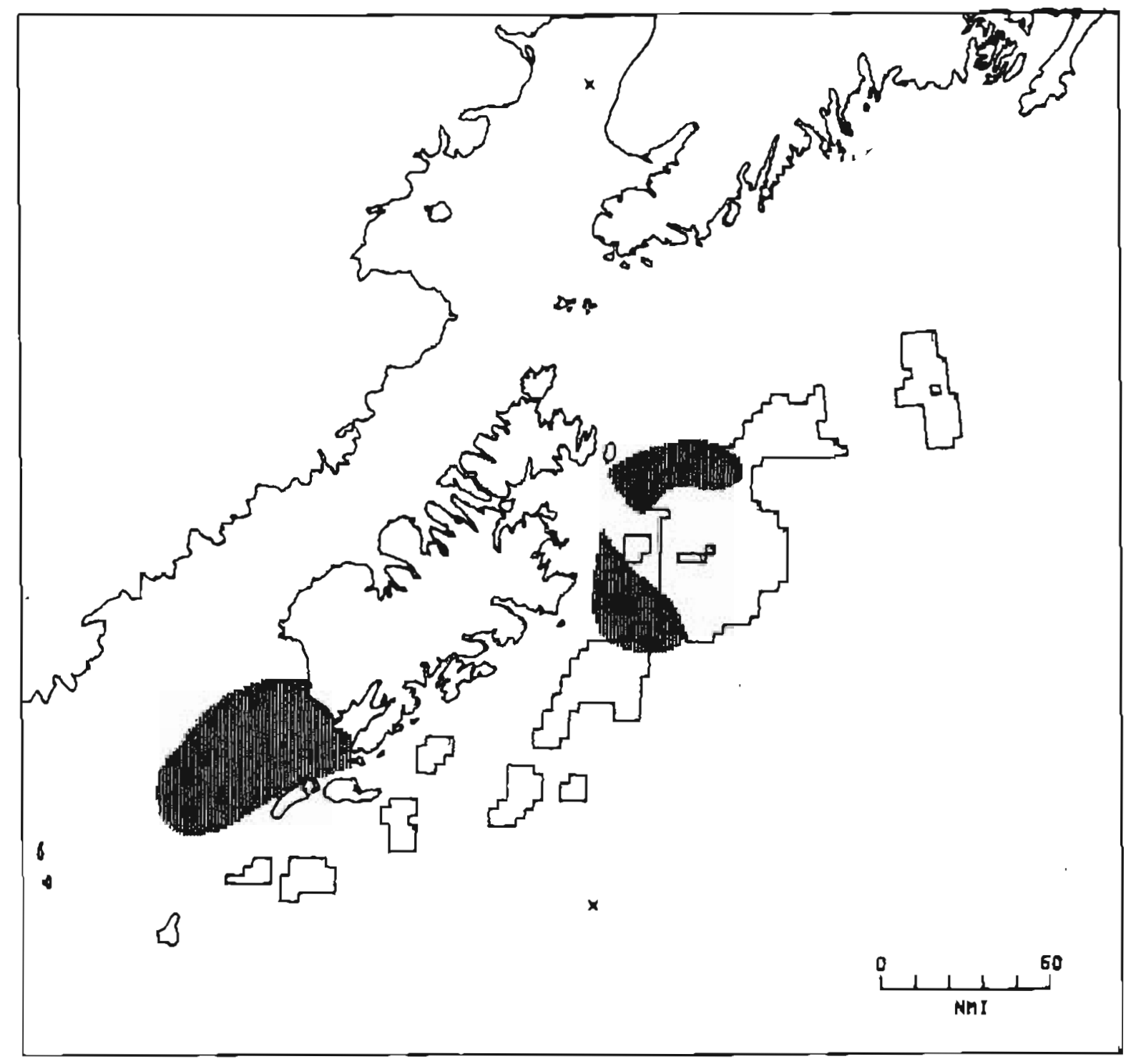

Figure A- 6.--Hatched area indicates spatial extent of tanner crab vital rearing areas. 
TANNER CRAB IMPORTANT REARING AREAS

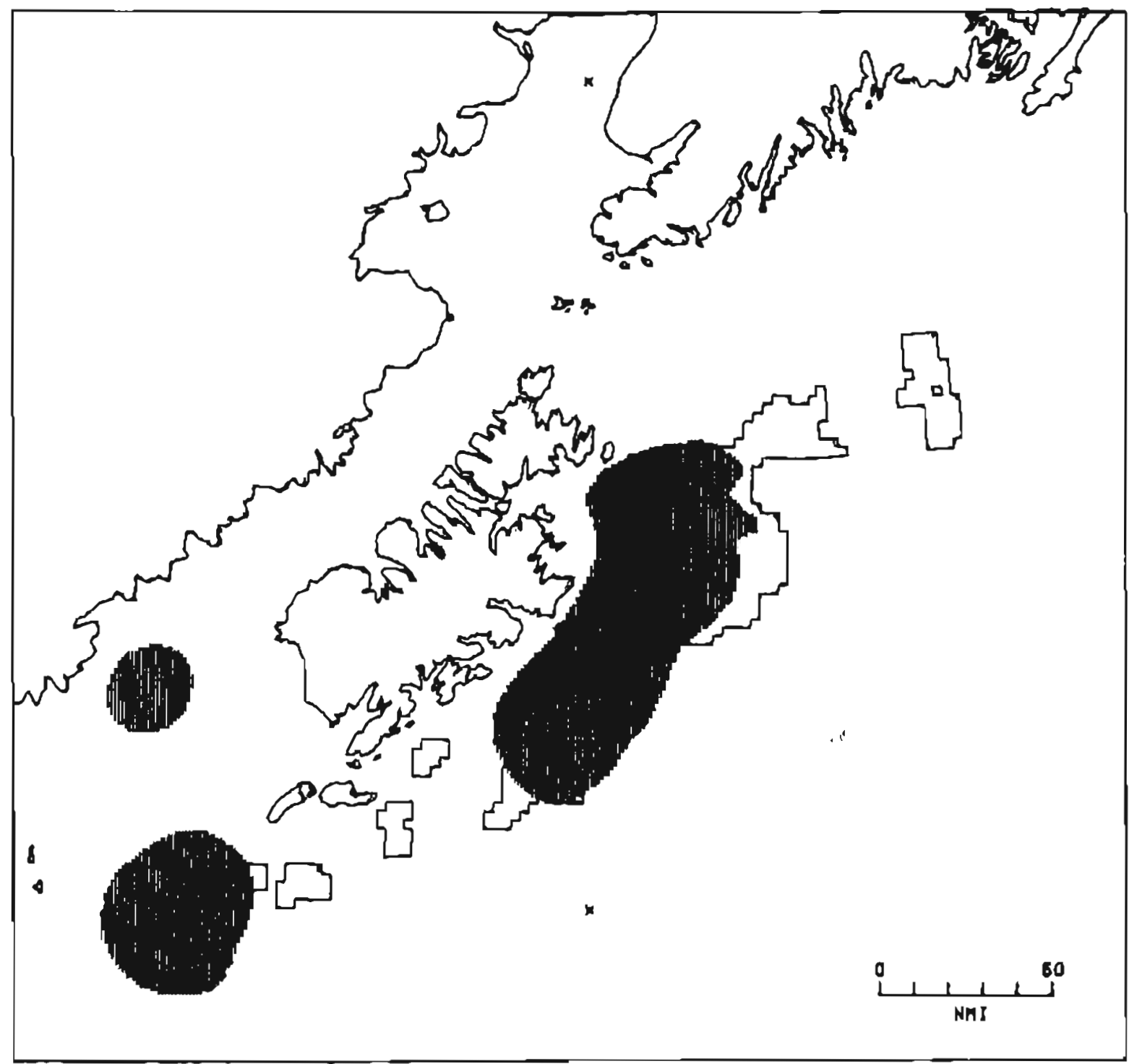

Figure A-7.--Hatched area indicates spatial extent of tanner crab important rearing areas. 
KING CRAB MATING AND HATCHING AREAS

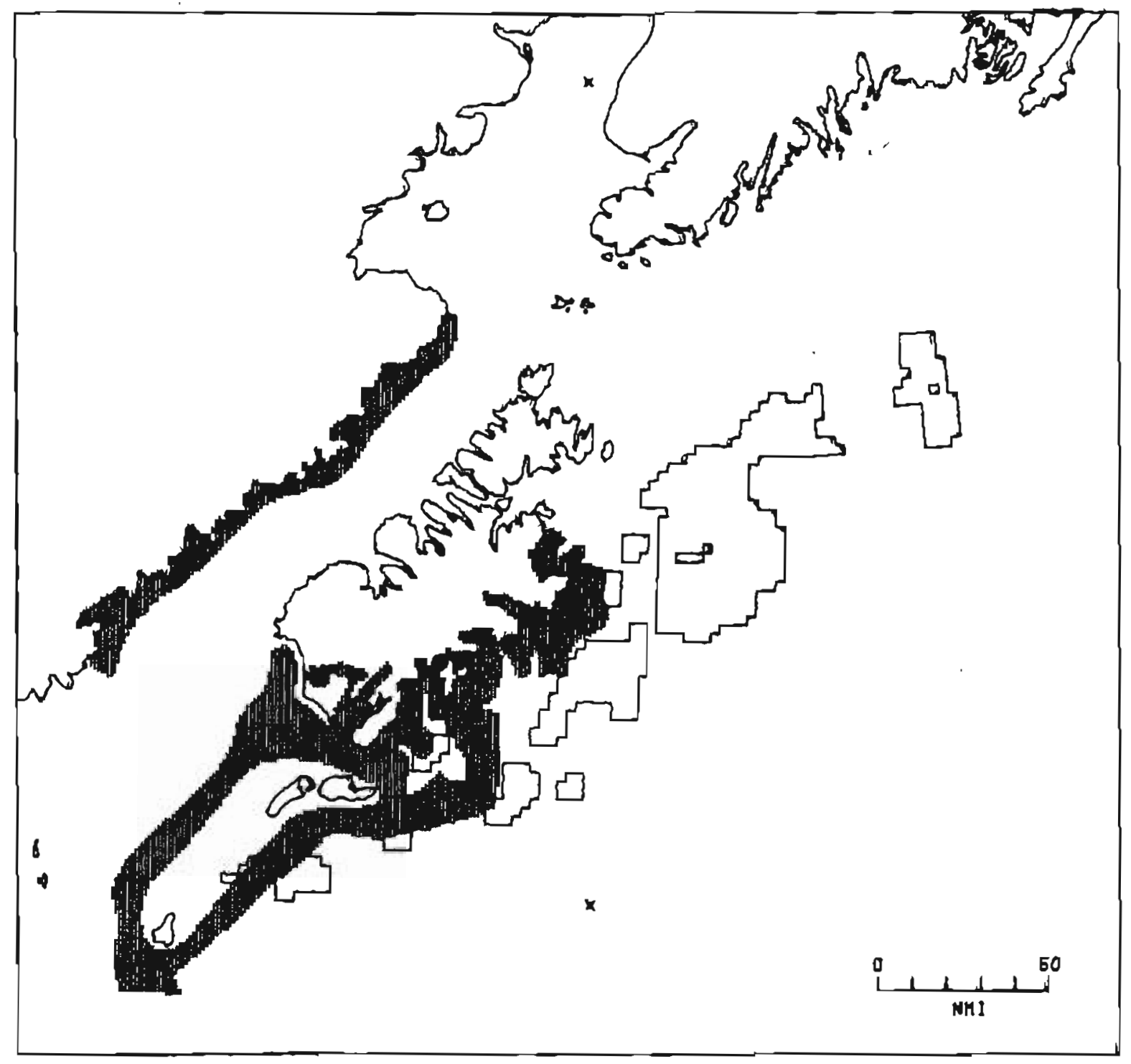

Figure A- 8.--Hatched area indicates spatial extent of king cxab mating and hatching areas. 
KING CRAB VITRL REARING AREAS

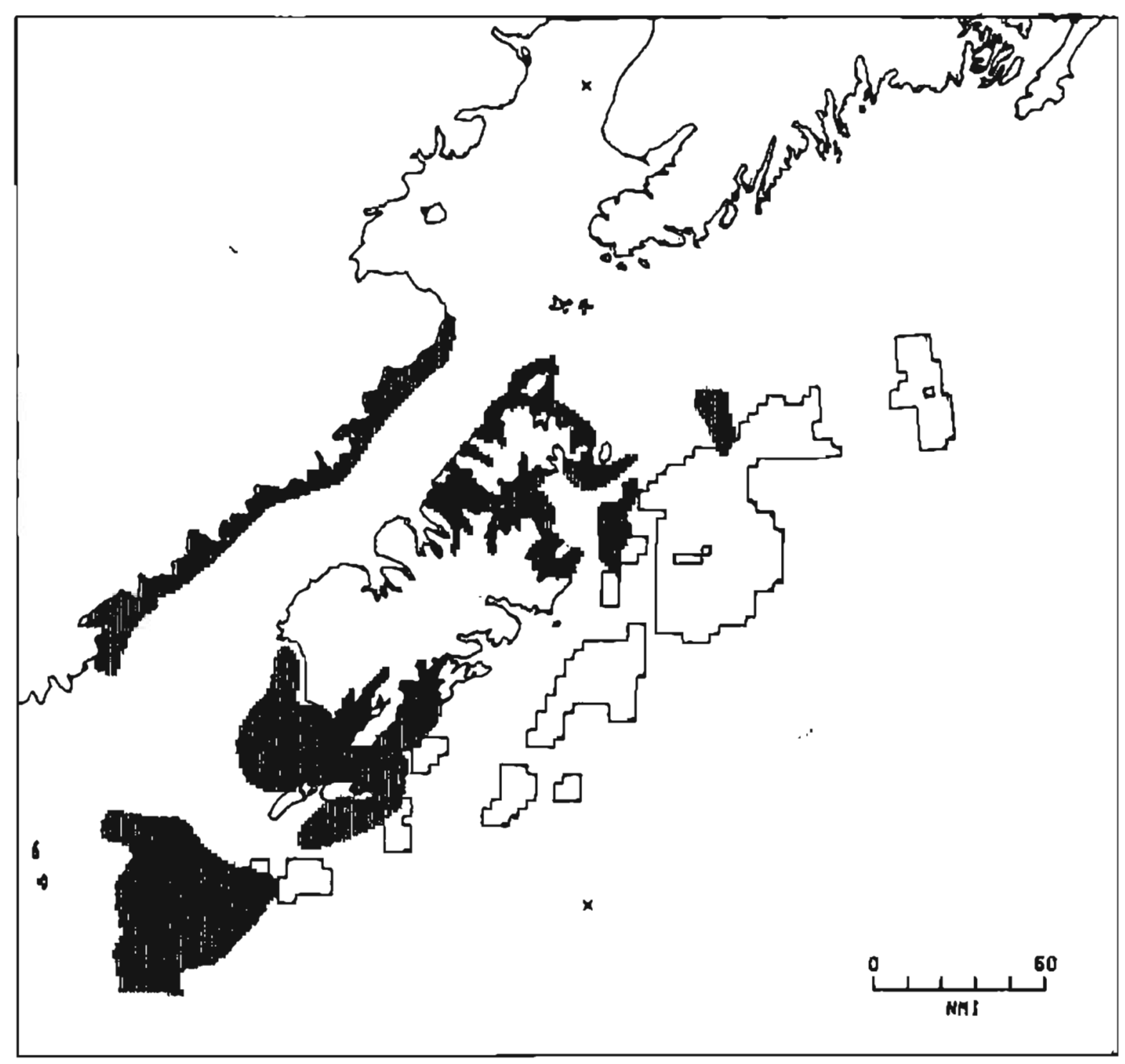

Figure A- 9.--Hatched area indicates spatial extent of king crab vital rearing areas. 
KING CRAB IMPORTANT REARING AREAS

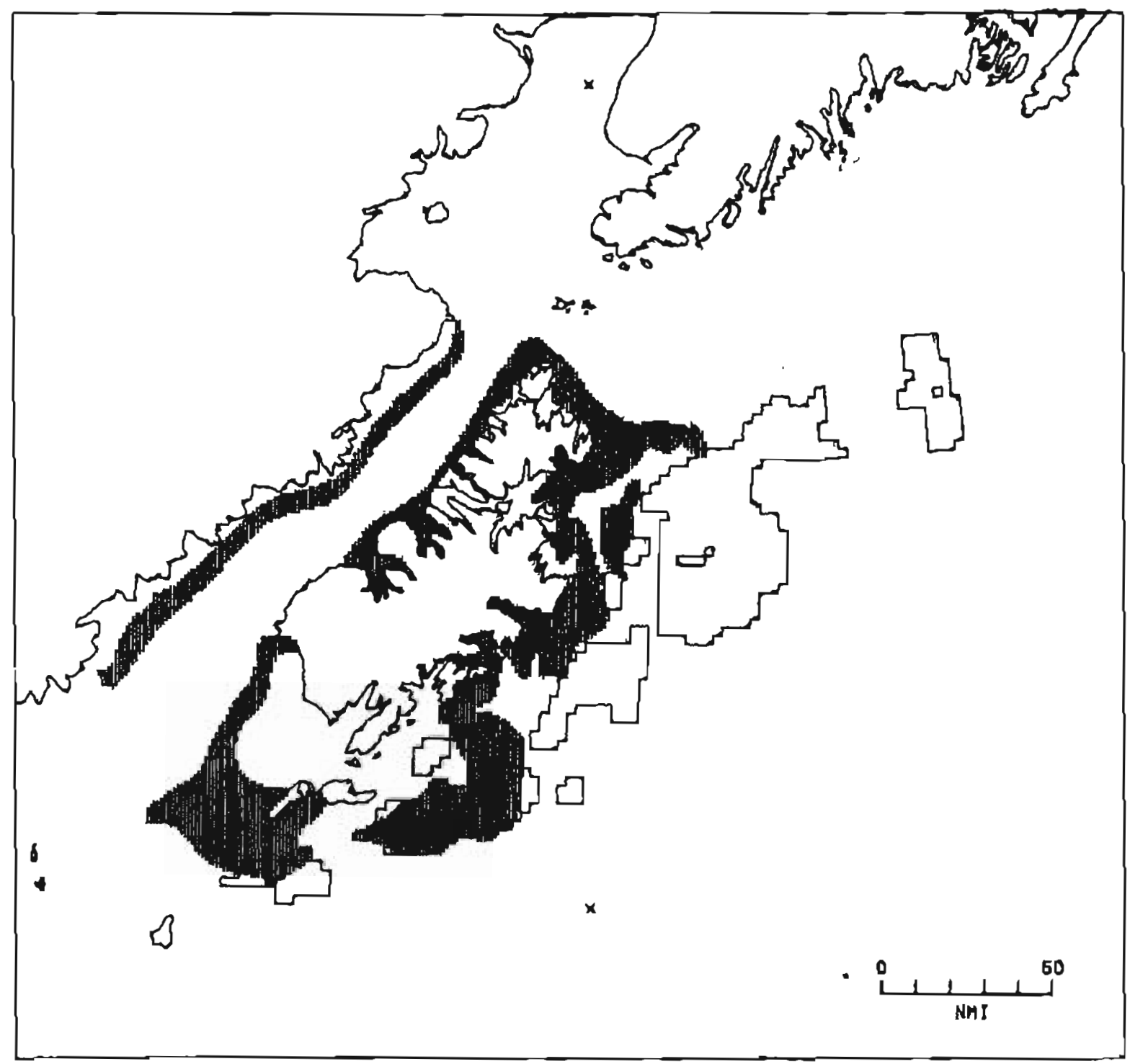

Figure A-10.--Hatched area indicates spatial extent of king crab important rearing areas. 
SHRIMP FISHING AREAS

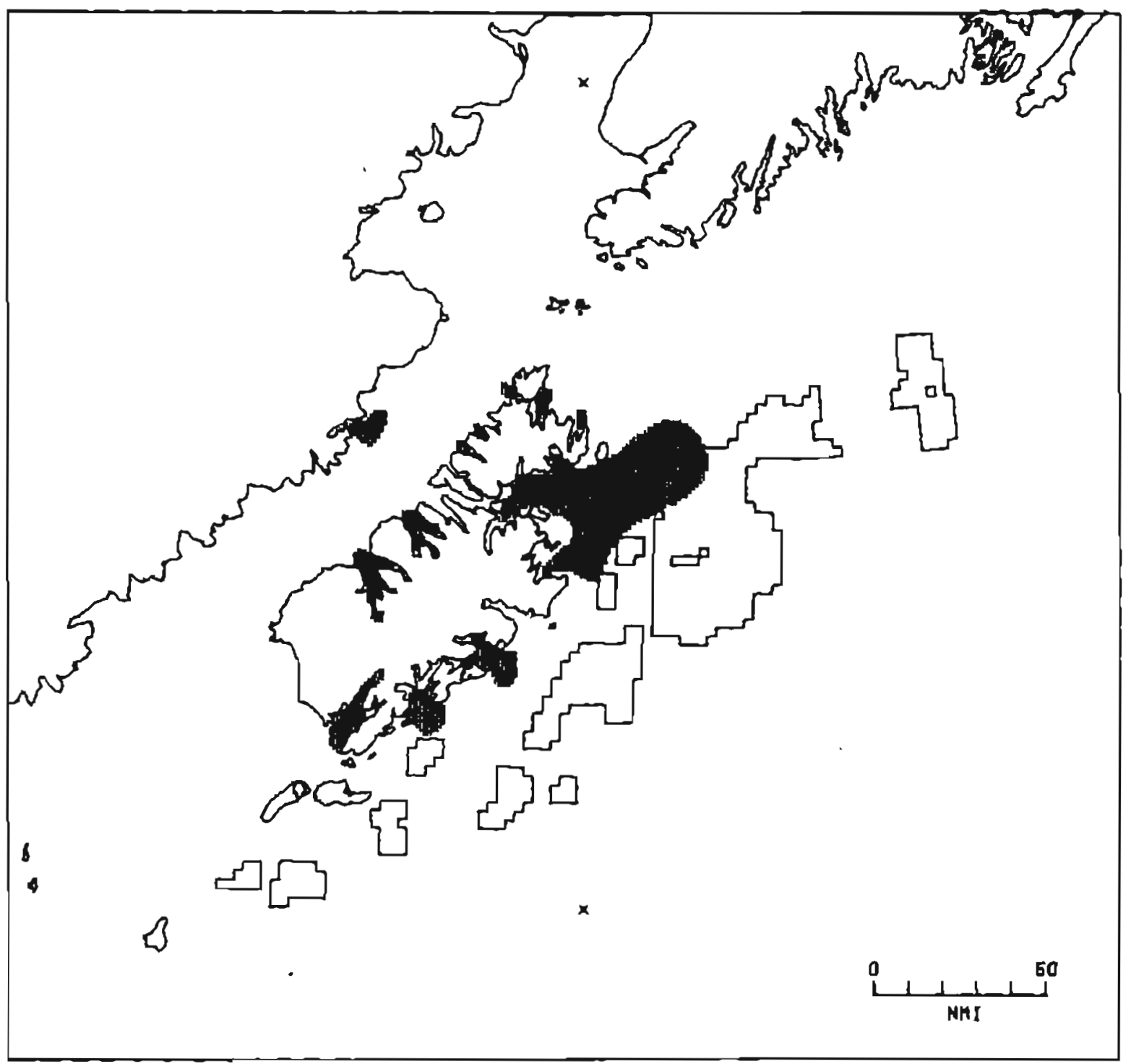

Figure A-11--Hatched area indicates spatial extent of shximp fishing areas. 
SHRIMP REPROOUCTION ANO HATCHING AREAS

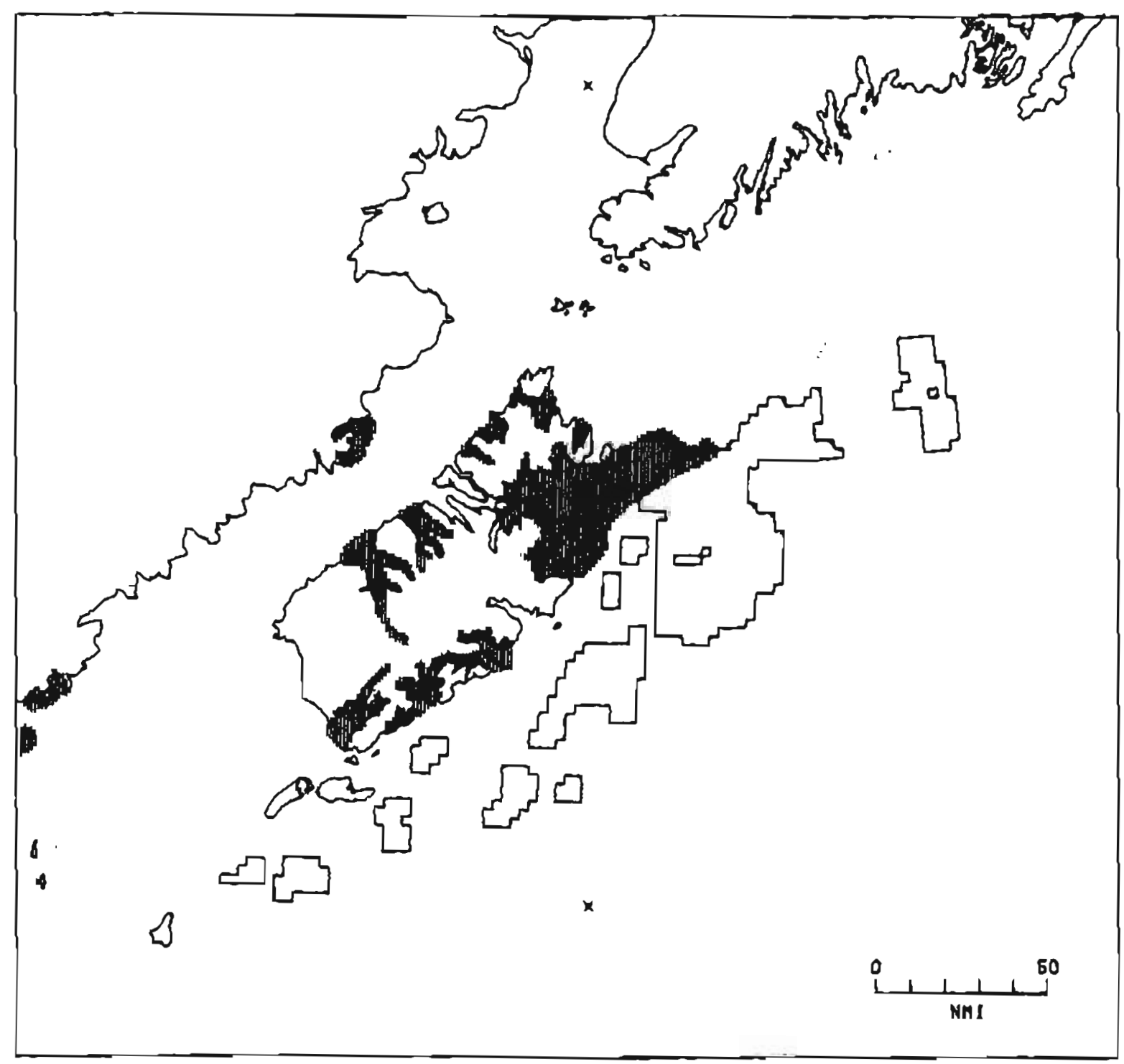

Figure A-12.--Hatched area indicates spatial extent of shrimp reproduction and hatching areas. 


\section{SERBIRD COLONIES}

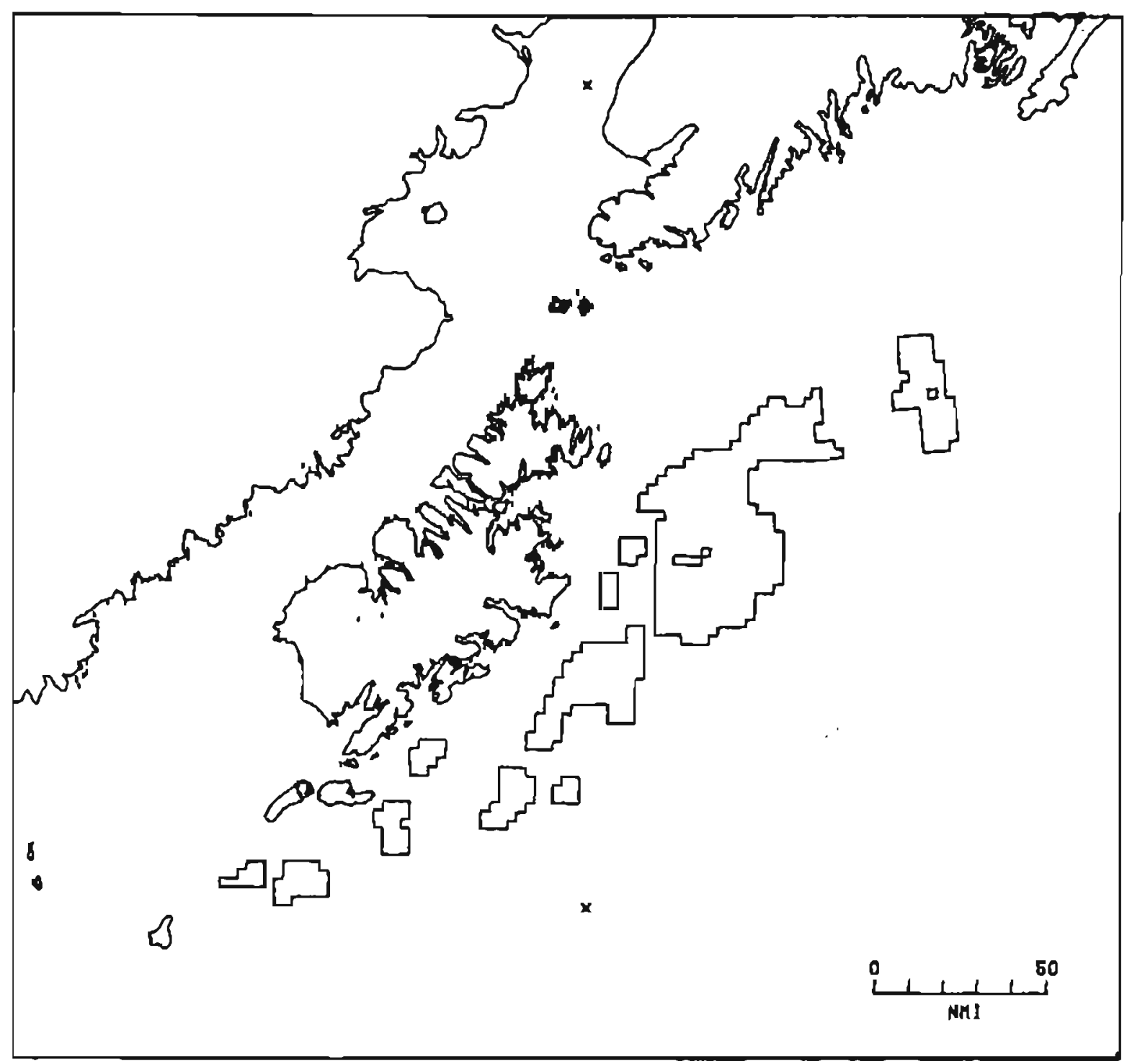

Figure A-13.--Hatched area indicates spatial extent of seabird colonies. 
BIRD DISTRIBUTION-SUMMER (JUNE, JULY, AUGUST)

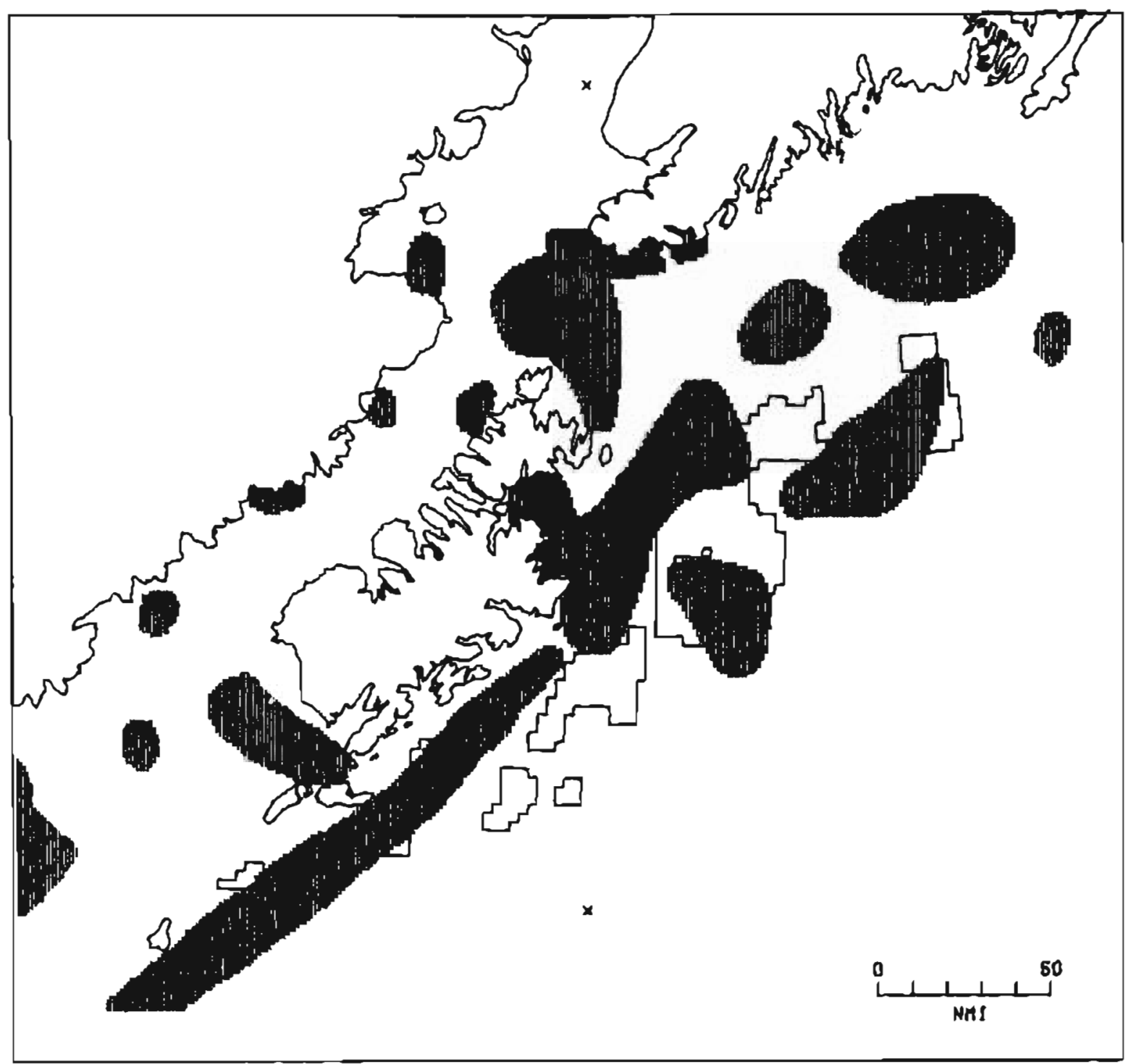

Figure A-14.--Hatched area indicates spatial extent of bird distribution sumer (June, July, August). 


\section{BIRD DISTRIBUTION-FALL (SEPTEMBER .OC TOBER, NOVEMBER)}

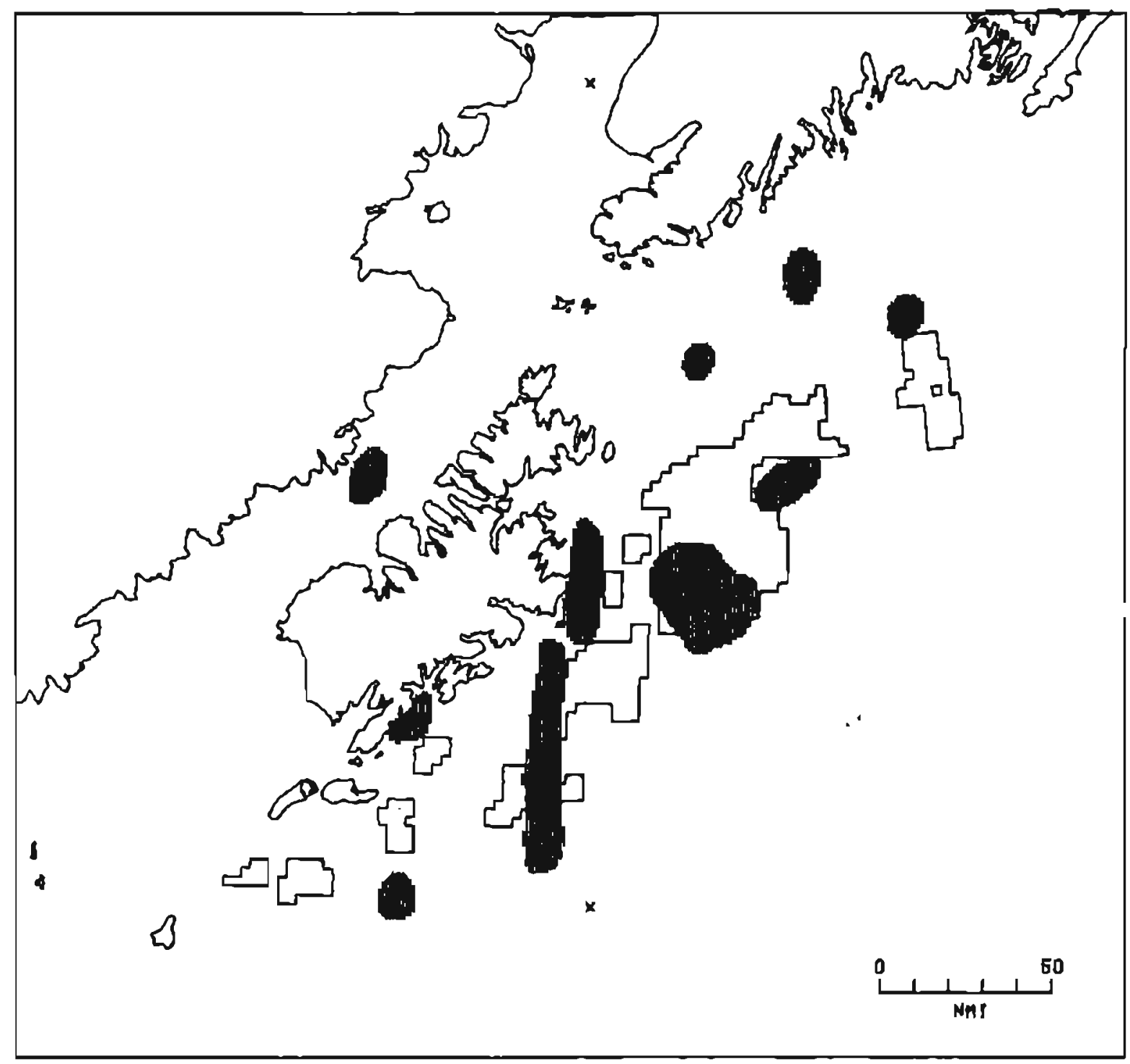

Figure A-15.--Hatched area indicates spatial extent of bird distribution fall (September, October, November). 


\section{IRD DISTRIBUTION-WINTER (DECEMBER. JANUARY, FEBRUARY)}

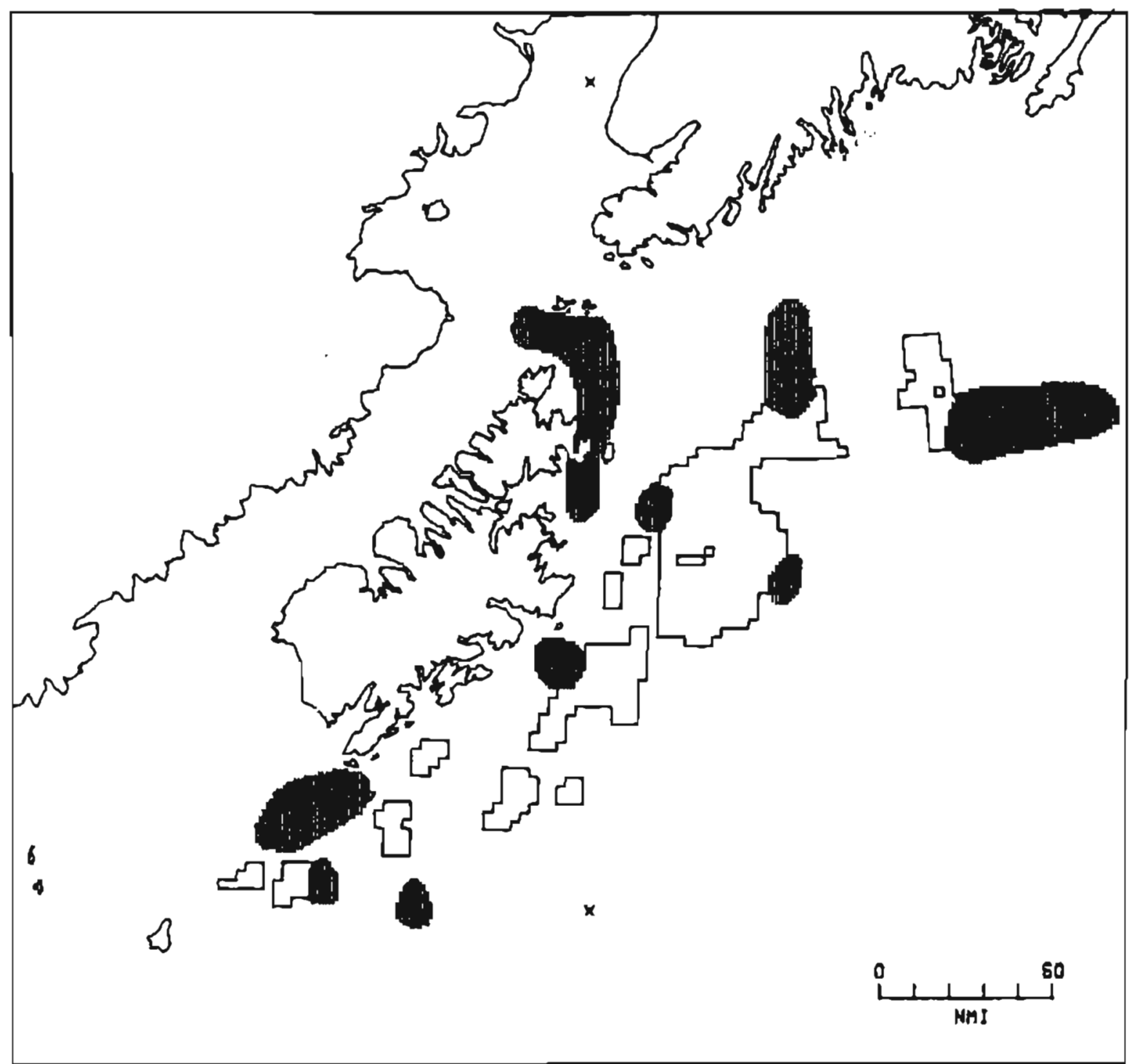

Figure A-16.--Hatched area indicates spatial extent of bird distribution winter (December, January, Februaxy). 


\section{BIRO DISTRIBUTION-SPRING (MARCH.APRIL, MAY)}

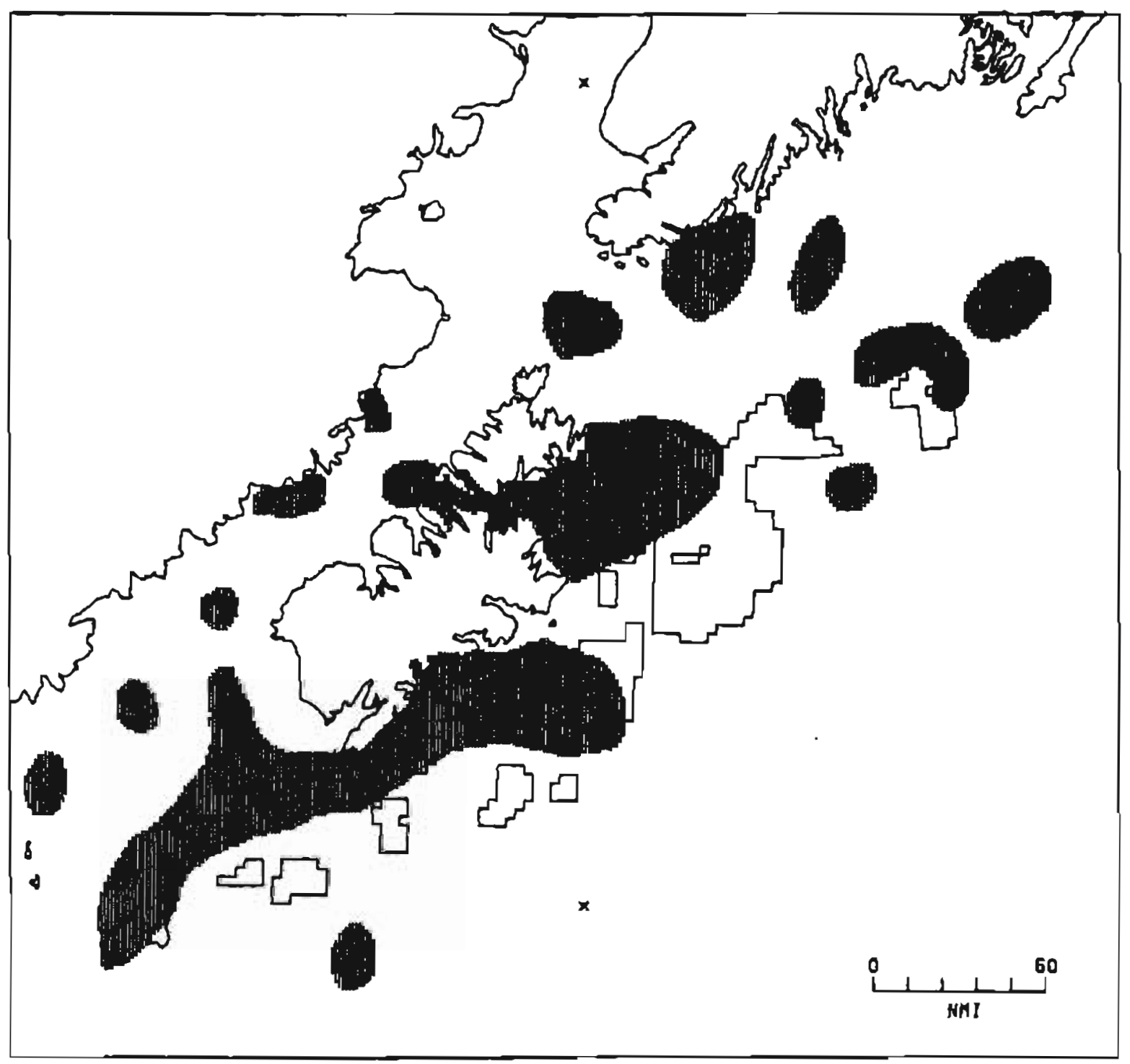

Bigure A-17.--Hatched area indicates spatial extent of bird atstribution spring (March, April, May). 
MARINE MAMMAL FORAGING AREAS

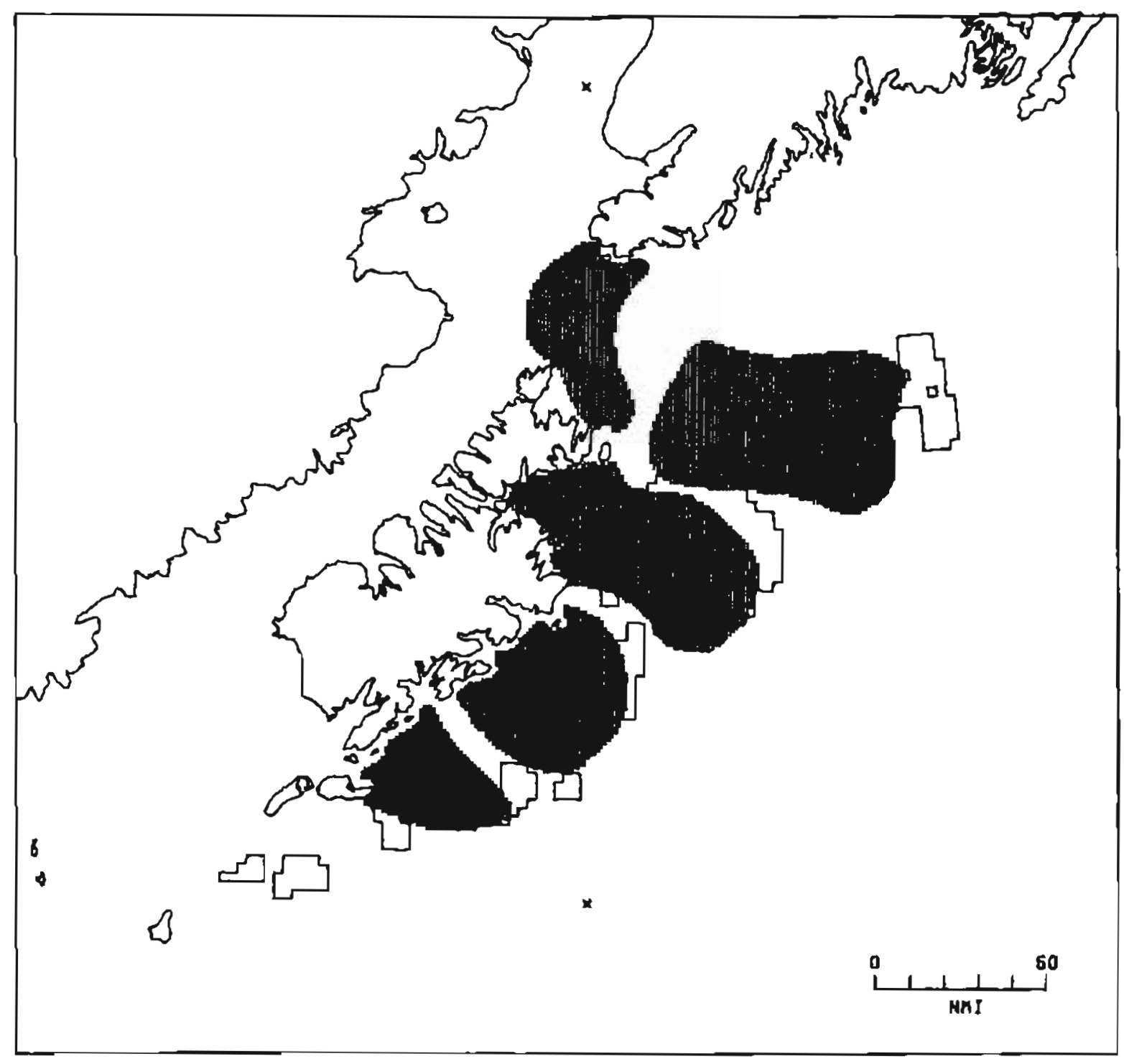

Figure A-18.-- Hatched area indicates spatial extent of marine mamal foraging areas. 
SEA LION ROOKERIES AND HAULING GROUNOS

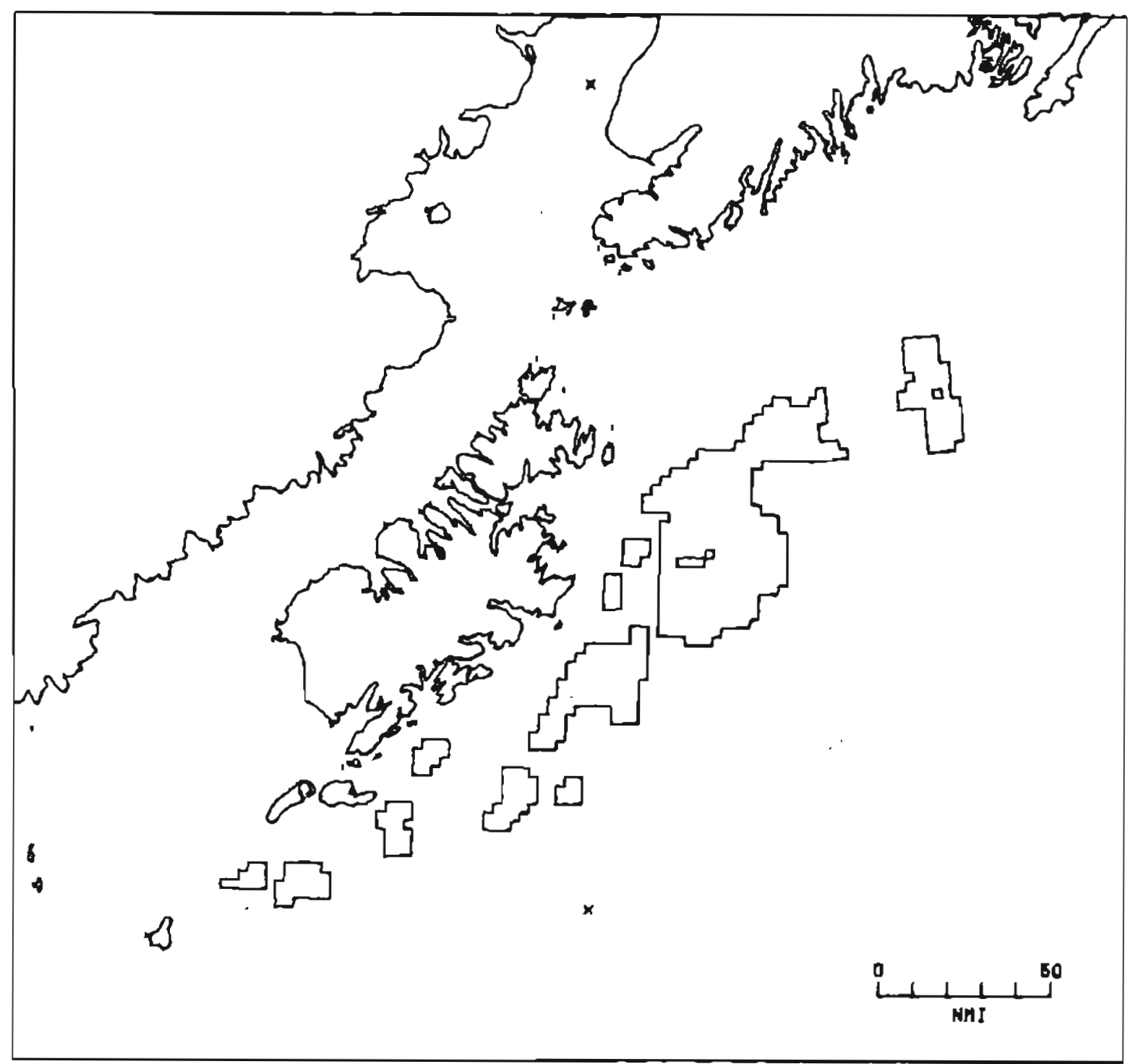

Figure A-19.--Hatched area indicates spatial extent of sea lion rookeries and hauling grounds. 
MARBOR SEAL ROOKERIES AND HAULING GROUNDS

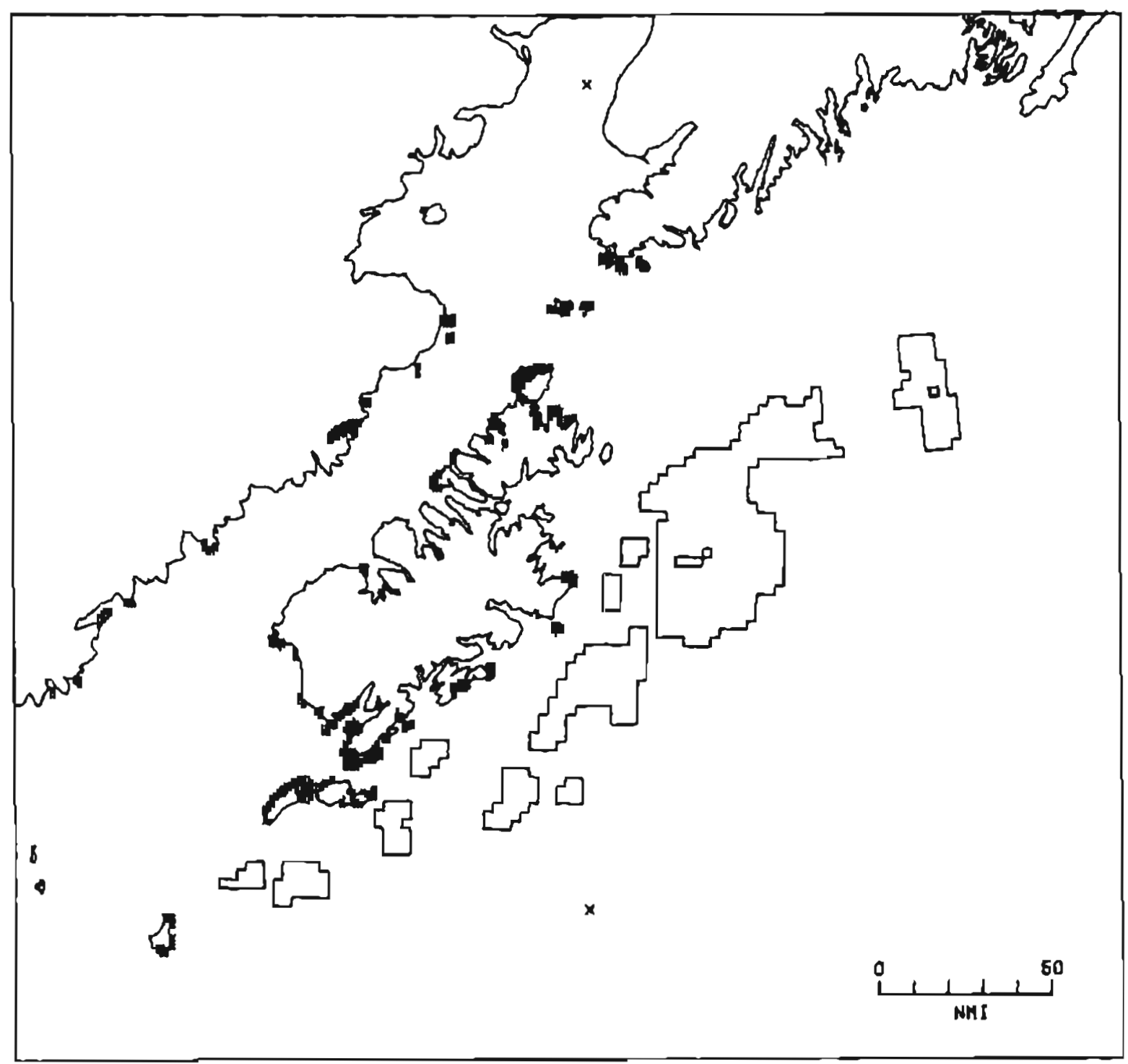

Figure A-20--Hatched area indicates spatial extent of harbor seal rookeries and hauling grounds. 
SEA OTTER CONCENTRRTION RREAS

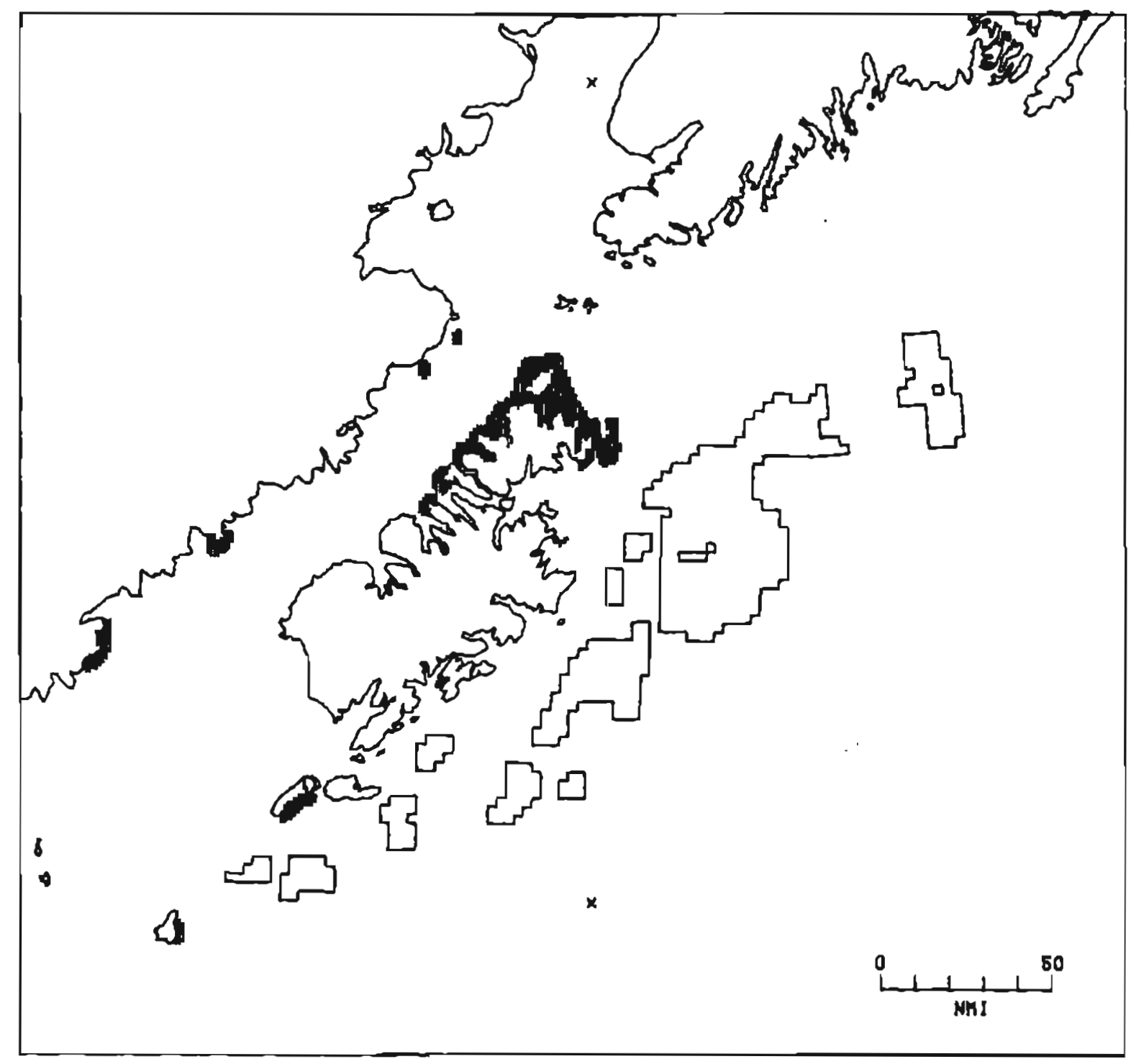

Figure A-21--Hatched area indicates spatial extent of sea otter concentration areas. 
ONSHORE KELP $100 \%$ COVER

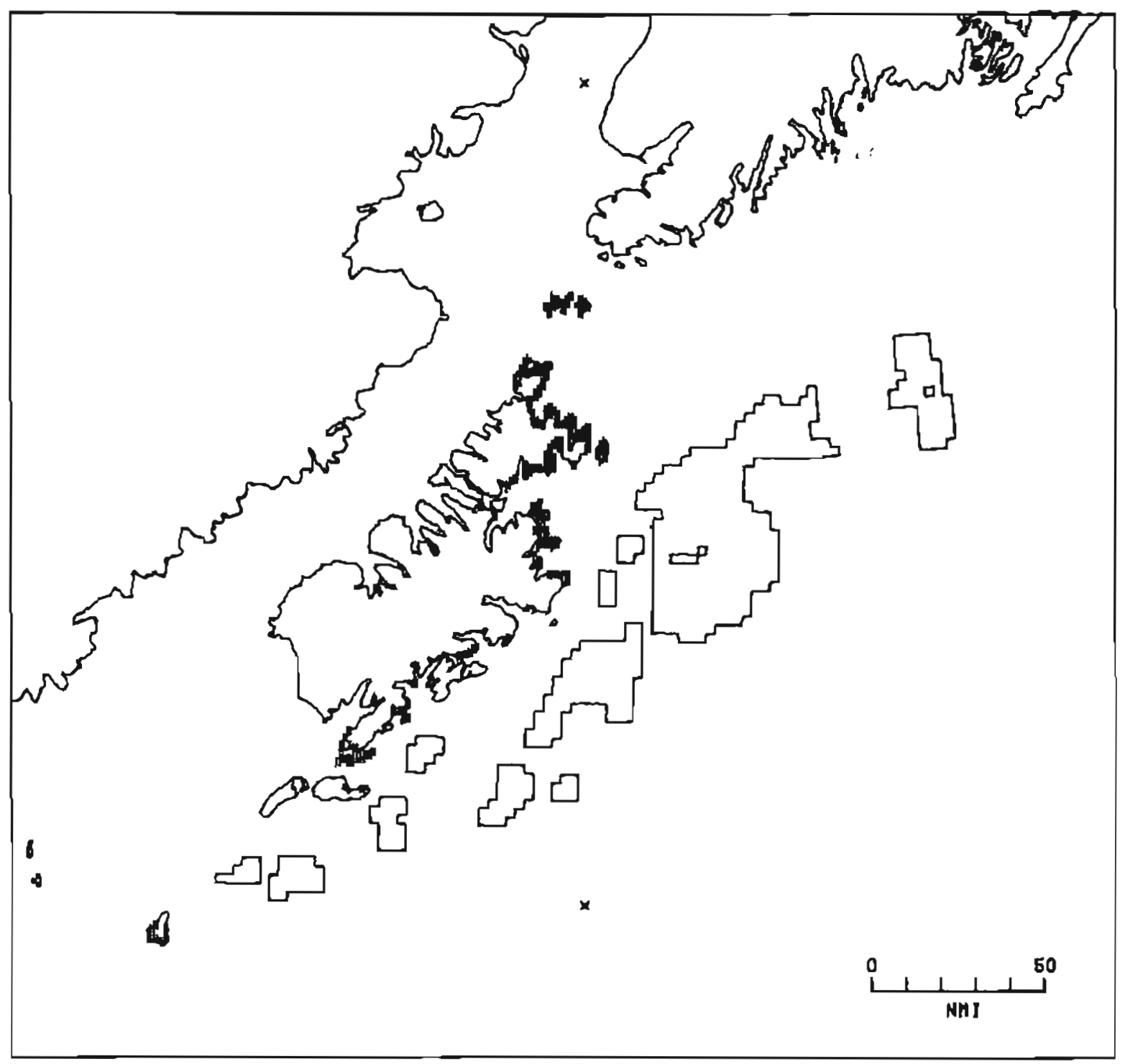

Figure A-22--Hatched area indicates spatial extent of onshore kelp 100 percent cover. 
FOREIGN FISHING AREAS

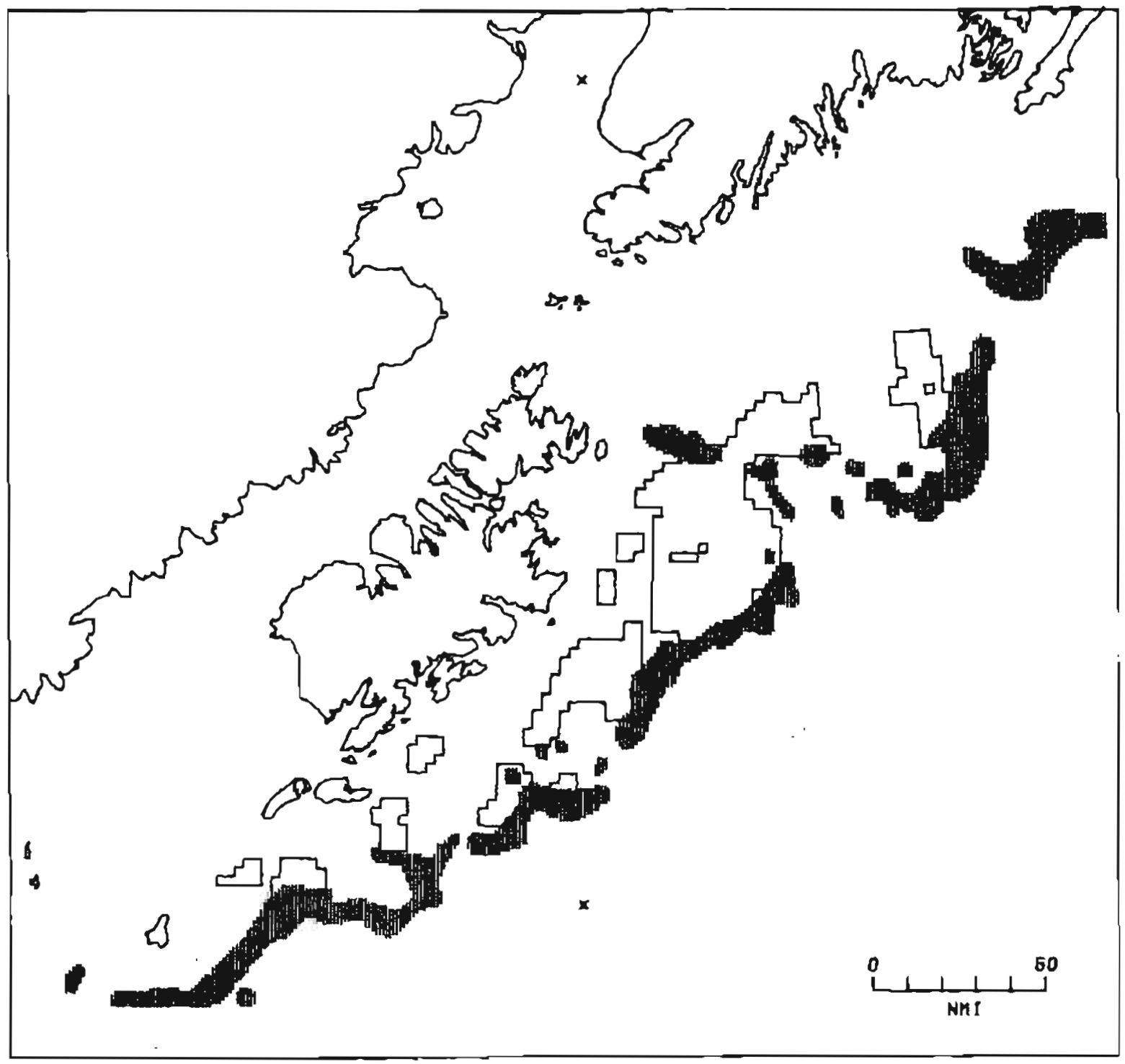

Figure A-23--Hatched area indicates spatial extent of foreign fishing areas. 
ARCHEOLOGICRL SITES

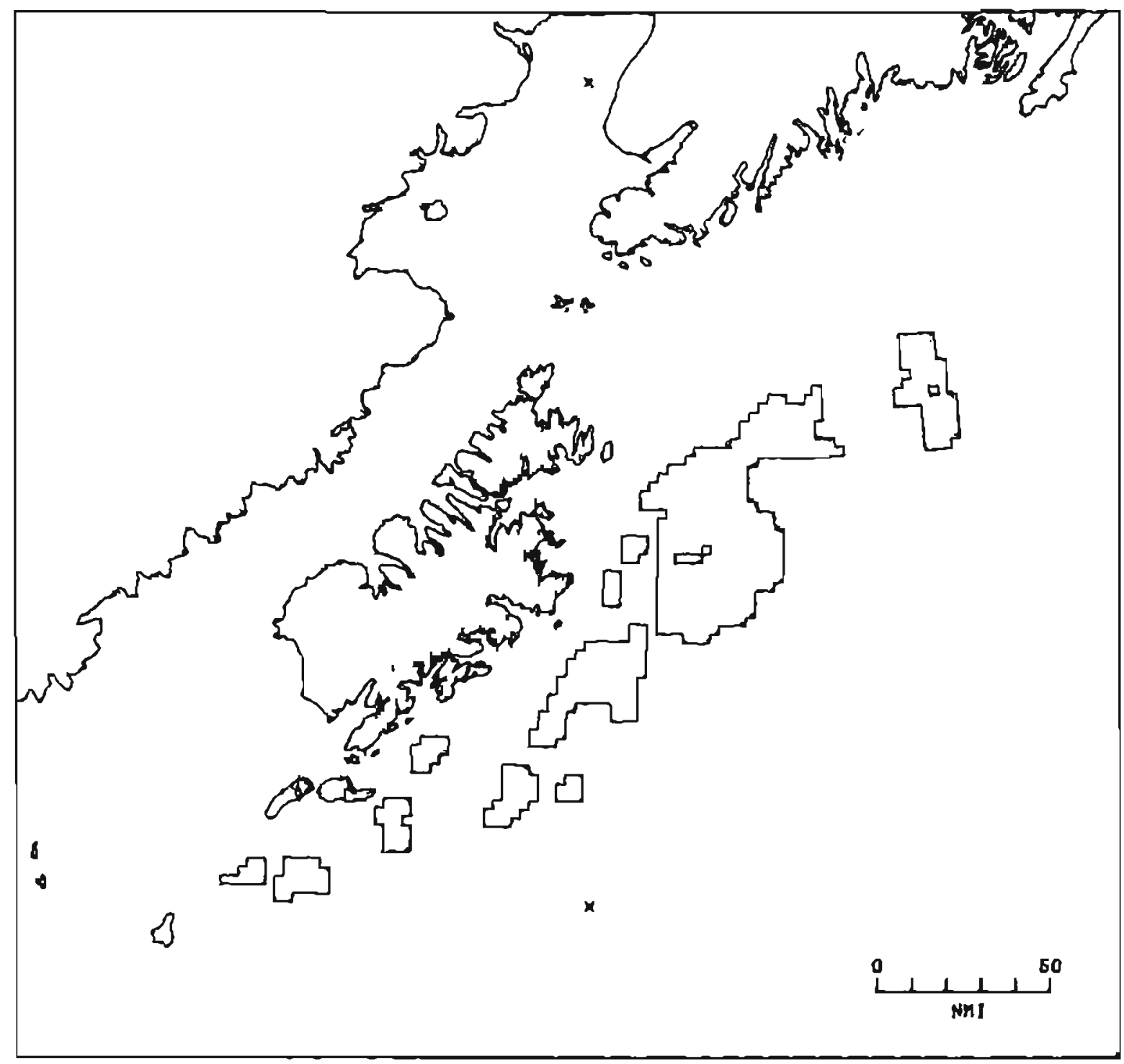

Figure A-24.-- Hatched area indicates spatial extent of archaeological sites. 